\title{
DETECTORES MULTIUSUÁRIOS PARA DS/CDMA - CANCELADORES DE INTERFERÊNCIA
}

\author{
Taufik Abrão e Paul Jean E. Jeszensky
}

\begin{abstract}
Resumo - Este trabalho faz uma revisão dos principais detectores multiusuários (MUD) subótimos para sistemas DSCDMA (Direct Sequence - Code Division Multiple Access). Nesta segunda parte são enfocados os Canceladores de Interferência (IC). Dentre os diversos MUD, os detectores IC resultam em ótimo compromisso desempenho $\times$ complexidade, mostrando-se uma opção factível na implementação de sistemas celulares de terceira geração (3G); em contrapartida, requerem acurácia na estimação dos parâmetros de canal (amplitude, atraso e fase da portadora de todos os sinais recebidos). Detectores multiusuários são capazes de operar sob o efeito near-far (NFRes) e combatem efetivamente a interferência de múltiplo acesso (MAI), resultando em aumento de desempenho em relação ao detector Convencional.
\end{abstract}

Palavras-chave: Sistemas DS-CDMA, detecção multiusuário subótima, eficiência assintótica multiusuário.

\begin{abstract}
This work makes a revision of the main suboptimal multiuser detectors (MUD) for DS-CDMA systems (Direct Sequence - Code Division Multiple Access). In this second part Interference Cancellation detectors (IC) are focused. Within various MUD, IC detectors result in optimum tradeoff performance $x$ complexity, being shown a feasible option in the implementation of cellular systems for third generation (3G); in compensation interference cancellation demands accurate estimation of the channel parameters (received amplitude, delay and phase). Multiuser detectors are capable to operate under the effect of near-far (NFres) and they combat the multiple access interference (MAI), resulting in performance improvement in relation to the Conventional detector.
\end{abstract}

Keywords: DS-CDMA systems, sub-optimum multiuser detection, asymptotic multiuser efficiency.

\section{INTRODUÇÃO}

O detector Convencional baseado no filtro casado resulta em capacidade sistêmica bem abaixo da capacidade do canal, além de sofrer a limitação de não ser resistente ao efeito nearfar, requerendo cuidadoso e rígido controle de potência. Assim, buscam-se algoritmos de detecção multiusuários objetivando a redução ou eliminação da MAI. Versões subótimas lineares fixas foram tratadas na primeira parte deste trabalho

Taufik Abrão está com o Departamento de Engenharia Elétrica da Universidade Estadual de Londrina (UEL). Paul Jean E. Jeszensky está com o Departamento de Engenharia de Telecomunicaçōes e Controle (PTC) e com o Laboratório de Comunicaçôes e Sinais (LCS) da EPUSP. E-mails: taufik @ uel.br, pjj@lcs.poli.usp.br Editores Ad Hoc responsáveis: Max H. M. Costa e Dalton Soares Arantes. Artigo submetido em 06/2000 e aceito em 04/2001.
[1].

Nos detectores multiusuários subótimos baseados em IC, tema deste segundo artigo, são geradas estimativas de interferência MAI e posteriormente subtraídas do sinal desejado. Existem basicamente três abordagens para se obter o cancelamento de interferência subtrativo: o Cancelamento ${ }^{1}$ de Interferência Paralelo (PIC), o Sucessivo (SIC) e o Detector de Decisão Realimentada Zero Forcing (ZF-DF). Estas estruturas pressupõem a explícita detecção e cancelamento de cada sinal de usuário a partir dos demais. Tais técnicas têm como pré-requisito o conhecimento dos parâmetros de canal, necessitando portanto de estimadores eficientes para as energias e atrasos dos sinais recebidos.

Receptores MUD subótimos baseados em IC são obtidos a partir de uma aproximação do detector de sequiências de máxima verossimilhança, MLSD, admitindo-se que dados, amplitudes e atrasos dos usuários interferentes (ou um subconjunto destes) sejam conhecidos. Também denominados de detectores de Decisão Realimentada (DF), esta classe de MUD opera com estimativas separadas da contribuição da interferência de cada usuário a fim de subtrair da saída algumas ou todas as interferências MAI vistas em cada usuário. O sinal residual resultante desta operação pode ser interpretado como um sinal single-user em presença de ruído de canal. Intuitivamente, se todos os sinais MAI puderem ser perfeitamente cancelados, o desempenho do receptor será idêntico ao do receptor Convencional em um ambiente single-user, resultando em máxima resistência ao efeito near-far. Na prática, a interferência jamais poderá ser cancelada perfeitamente e a eficiência será sempre menor que 1 .

Os detectores IC subtrativos são implementados normalmente empregando-se vários estágios, onde a expectativa é de decisões melhoradas a cada novo estágio. São similares aos equalizadores realimentados em [2], empregados no combate à ISI.

A principal vantagem de detectores MUD não lineares IC consiste no compromisso ótimo entre complexidade de implementação $x$ desempenho. $\mathrm{E}$ a principal desvantagem desta técnica condiciona a melhoria de desempenho à obtenção de estimativas precisas dos níveis de energia de cada usuário.

O primeiro trabalho sobre PIC é atribuido a Varanasi e Aazahang [3]. Enquanto que [4] representa um artigo clássico para o tratamento do SIC. Há ainda abordagens híbridas: GSIC (Group-wise SIC) e GPIC [5], [6]. GIC são esquemas multiestágios com estimativas melhoradas em um modo iterativo. A estimativa do canal é feita simultaneamente sobre um grupo de usuários e cancelamentos são então realizados em paralelo ou de modo sucessivo.

I ou Cancelador 
Detectores baseados em IC dependem de decisões feitas sobre os bits dos usuários interferentes e utilizam estas informações para obter cancelamento de interferência do usuário de interesse, podendo envolver a reconstrução do sinal interferente modulado objetivando subtraí-lo do sinal de entrada. Versões adaptativas necessitam de acurácia na estimação dos parâmetros atraso e potência [7], [8].

Elevado tempo de demodulação, proporcional ao número de usuários, é a principal desvantagem dos receptores SIC, o que em sistemas altamente carregados toma-se impraticável. Adicionalmente requerem a ordenação dos usuários em termos de suas energias ou correlações recebidas, resultando em complexidade adicional na implementação.

Devido à sua baixa complexidade, alta capacidade, baixo tempo de latência e robustez, o PIC multiestágio torna-se uma técnica atraente na implementação de sistemas práticos. A única desvantagem consiste na necessidade de um relativo controle de potência. No entanto, a capacidade do PIC multiestágio será significativamente maior que a abordagem SIC, caso seja garantido perfeito controle de potência $(N F R=$ $0)$.

Há duas abordagens para se realizar o cancelamento de interferência subtrativo, ambas equivalentes do ponto de vista teórico:

\section{- Desespalhamento/Respalhamento em Banda Larga} (Wideband despread/respread): envolve a reconstrução do sinal antes do cancelamento;

- Pós-Detecção (Post-Detection Cancellation): emprega a correlação cruzada entre usuários e as estatísticas de decisão $\left(Z_{i}^{(s)}\right)$ na reconstrução das componentes da interferência após a detecção.

Quando as correlações cruzadas não mudarem rapidamente, a abordagem Pós-Detecção pode ser mais rápida. No entanto, em sistemas práticos, a abordagem de cancelamento em Banda Larga é mais simples de ser implementada [6], [9].

Algumas destas soluções de detectores não lineares utilizam tentativas de decisões de dados ${ }^{2}$ na estimação da interferência, enquanto outras utilizam-se apenas da decisões finais dos usuários interferentes no processo de detecção. $O$ esquema que emprega tentativas de decisões é denominado Decisão Abrupta em cancelamento de interferência (HD-IC), cujos bits obtidos nos circuitos de decisão são diretamente realimentados; não é linear, requerendo estimativas realistas para as amplitudes recebidas. Caso não se utilize de tentativas na decisão dos dados, o esquema é denominado Decisão Suave para cancelamento de interferência (SD-IC); este esquema emprega estimativas lineares de dados na obtenção da estimativa conjunta de dados e amplitudes do usuário de interesse, resultando em maior simplicidade de implementação.

Detectores subtrativos requerem um mínimo de confiabilidade em suas decisões iniciais. Caso seja possível obter estimativas confiáveis das amplitudes, o detector de cancelamento de interferência do tipo HD-IC geralmente terá desempenho superior ao detector do tipo SD-IC.

Canceladores de interferência são também apropriados para operarem em sistemas CDMA dinâmicos, onde os

\footnotetext{
2Internamente ao demodulador do usuário de interesse.
}

parâmetros de sistema devem ser atualizados freqüentemente devido às constantes mudanças no número de usuários, formas de onda de espalhamento, atrasos e amplitudes recebidas.

Um abordagem alternativa para a implementação de receptores IC consiste na remoção da interferência na saída de um banco de filtros casados sem lançar mão da regeneração dos sinais interferentes. Em [10] foi proposto um meio adaptativo para se obter o cancelamento que consiste em subtrair da saída do filtro casado correspondente ao usuário de interesse valores estimados de uma soma ponderada dos interferentes, Figura 1. Esta técnica não requer seqüência de treinamento, porém exige conhecimento de todos os usuários ativos para implementar o banco de filtros casados e formar boas estimativas iniciais das interferências no Descorrelacionador.

Definitivamente, receptores baseados em cancelamento de interferência são uma grande promessa para a implementação de sistemas DS/CDMA de alta capacidade e desempenho.

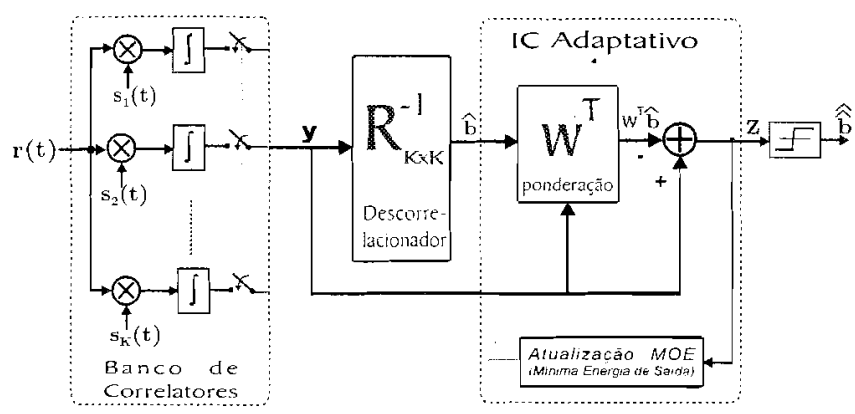

Figura 1. Cancelamento de Interferência multiusuário adaptativo a partir de ponderação baseada em energia mínima de saída (MOE).

\section{DETECTOR SIC}

O cancelador de interferência sucessivo emprega abordagem de busca serial para cancelar a MAI. Caso uma decisão tenha sido feita sobre o bit de um usuário interferente, então este sinal pode ser recriado no receptor e subtraído do sinal recebido. Admite-se conhecidas as sequiencias de espalhamento de todos os usuários, porém as energias dos usuários individuais são estimadas. Isto cancelará o sinal interferente supondo que a decisão esteja correta; caso contrário, ter-se-á a duplicação da contribuição do sinal interferente. Uma vez que a subtração tenha sido feita, o receptor admitirá que o sinal resultante contém um usuário interferente a menos, e o processo pode ser repetido até que $K-1$ usuários tenham sido demodulados.

Visando obter as decisões intermediárias, o cancelamento sucessivo utiliza as decisões geradas nos filtros casados single-user, os quais negligenciam a presença de interferentes. Uma vez que decisões intermediárias errôneas afetarão a confiabilidade de todas as decisões de bits sucessivos, então a ordem com que os usuários são demodulados afetará o desempenho final do SIC. Uma abordagem de demodulação empregada frequentemente consiste em demodular os usuários em ordem decrescente das potências recebidas. No entanto, isto não conduz necessariamente ao melhor 


\section{Taufik Abrão e Paul Jean E. Jeszensky \\ Detectores Multiusuários para DS/CDMA - Canceladores de Interferência}

desempenho. Tal estratégia falha em não levar em conta as correlações cruzadas entre os usuários.

Alternativamente, o processo de ordenação das energias dos sinais recebidos em um SIC pode ser realizado a partir das correlaçôes das seqüências de espalhamento no receptor, $s_{k}$, e o sinal recebido $r(t)$ [4]. Os valores de correlação obtidos a partir de um banco de correlatores convencional são então introduzidos em um selector, o qual determina o valor da maior correlação, selecionando o usuário correspondente, $z_{i}$, para decodificação e cancelamento. Estes valores de correlação formam a base para a estimação das amplitudes e manutenção da ordem de cancelamento $0^{3}$, em oposição à estratégia da estimação das potências separadas. Na Figura 2, a operação de cancelamento de interferência para o $i$-ésimo usuário é precedida pela ordenação das energias dos sinais recebidos. baseada em: a) estimação das amplitudes; ou b) uma operação de correlação entre sinal recebido e as sequiências de espalhamento; neste caso, as estimativas das amplitudes, $A_{i}$, não são necessárias. Em um SIC são implementadas as seguintes operações:

1. deteç̧ão do sinal mais forte, $; i$, a partir de um detector convencional;

2. decisão abrupta em $\approx_{i}$;

3. regeneração e estimação do sinal recebido para o usuário mais forte no $i$-ésimo cancelamento, $\hat{\sim}_{i}$, empregando-se decisão de dados da etapa 1. conhecimento da seqüência de espalhamento. s.. estimação das amplitudes. fases e desaiustes temporais:

$\therefore$ cancelanento de $;$. a partir do sinal total recebido, $r(t)$, produzindo uma versão parcialmente limpa deste sinal, $r_{i+1}(t)$.

Admitindo-se estimação precisa de $z_{i}$ na etapa 3 , da $i-$ ésima etapa de cancelamento resultarão:

1. decisão do usuário mais forte ;

2. versão modificada do sinal recebido, $r_{i+1}(t)$, sem a parcela da MAI referente ao $i$-ésimo usuário mais forte $z_{i}$.

Este processo é reproduzido sucessivamente até que o usuário de menor energia ou correlação seja demodulado: o $k$-ésimo estágio gera uma estimativa de decisão de dados adicional, $\hat{\grave{z} k}$, e uma versão mais limpa do sinal recebido, $r_{k+1}(t)$. Apesar da ordenação dos usuários baseada nos valores de correlação resultar, para certos casos, em melhor desempenho, há duas razões para se adotar o cancelamento dos sinais em ordem descendente de potência:

1. facilidade de aquisição e demodulação do usuário de maior amplitude com grande chance de se obter decisão correta:

2. maior benefício para os remanescentes; o usuário de maior amplitude não se beneficiará com qualquer redução de MAI, equivalendo à detecção convencional para este usuário; porém, os mais fracos, potencialmente, terão imensa redução de MAI.

${ }^{3}$ Adicionalmente, as saídas dos correlatores auxiliam na obtenção da fase durante processo de demodulação não coerente.
Restrição no número de usuários cancelados em um SIC pode ser imposta quando estimativas de amplitude confiáveis não puderem ser obtidas para todos os usuários ativos e/ou quando atrasos de processamento excessivos não puderem ser tolerados, uma vez que em SIC o tempo de deteç̧ão é proporcional a K.T. Procede-se então ao cancelamento sucessivo dos usuários pertencentes ao grupo mais forte e tratamse os usuários do grupo mais fraco como ruído no processo de detecção de qualquer usuário pertencente a este grupo.

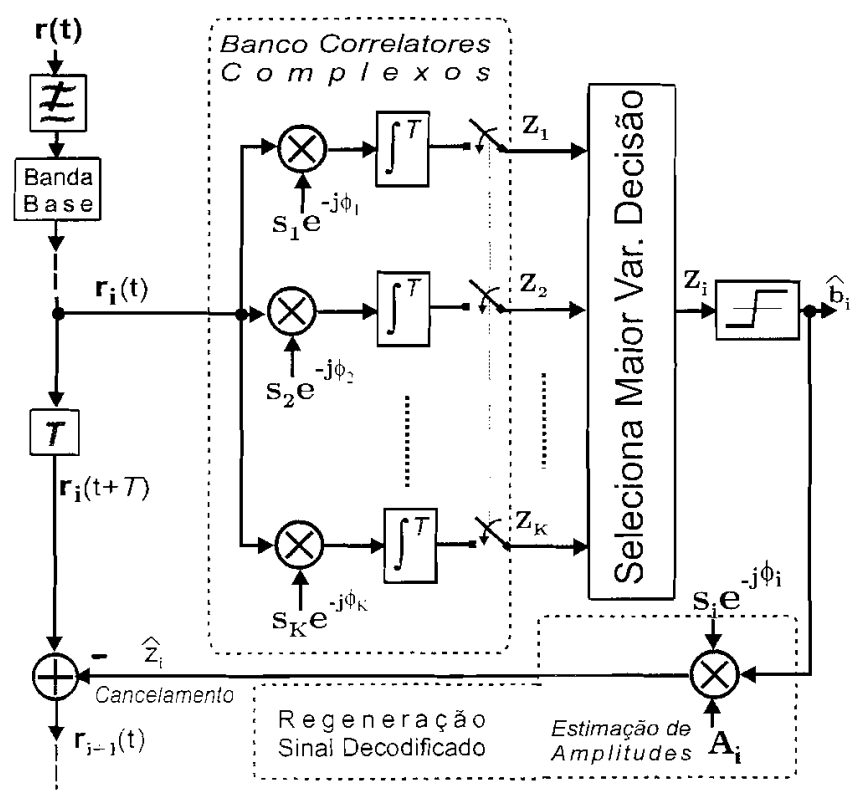

Figura 2. Etapas de detecção do i-ésimo usuário em um SIC Pós-Detecção, com decisão hard e modulação BPSK coerente.

O Detector SIC requer uma quantidade mínima de hardware adicional, porém resulta em um aumento substancial de desempenho em relação ao detector convencional. No entanto, existem as seguintes dificuldades de implementação:

- atrasos adicionais de período de bit. T. a cada estágio de cancelamento; deve-se buscar compromisso entre número de usuários cancelados e quantidade de atraso a ser tolerado;

- reordenação dos sinais dos usuários ativos, uma vez que o perfil das potências mudam. Deve-se estabelecer compromisso entre precisão na ordenação das potências e complexidade aceitável de processamento;

- quando a estimativa inicial dos dados não for confiável, mesmo que estimativas de tempo, amplitude e fase sejam perfeitas, o efeito da interferência de cada bit incorreto sobre a SNR será quadruplicado em termos de potência. Em SIC, faz-se necessário pelo menos que a estimativa dos dados mais fortes sejam confiáveis.

Partindo-se do procedimento de ordenação das energias baseado nas correlações [4], após $i$-cancelamentos sucessivos, a variável de decisão para o $(i+1)$-ésimo usuário em um sistema com demodulação BPSK coerente será:

$$
\hat{Z}_{i+1}=\frac{1}{2}\left(A_{i+1} b_{i+1}+C_{i+1}\right) \text {. }
$$


onde a componente de ruído total $C_{i+1}$ é dada por:

$$
\begin{gathered}
C_{i+1}=\underbrace{\sum_{k=i+2}^{K} A_{k} I_{k . i+1}\left(\tau_{k . i+1}, \phi_{k, i+1}\right)}_{\text {MAI (Us. Nầ Cancelados) }}+\underbrace{\left(n_{i+1}^{I}+n_{i+1}^{Q}\right)}_{\text {AWGN }} \\
-\underbrace{\sum_{j=1}^{i} C_{j} I_{j, j+1}\left(\tau_{j, j+1}, \phi_{j, j+1}\right)}_{\text {Cancelamento Imperfeiro Cumulativo }}
\end{gathered}
$$

com $n^{I}$ e $n^{Q}$ componentes em fase e quadratura do AWGN e o termo correlação cruzada dado por:

$$
\begin{aligned}
& I_{k . \ell}\left(\tau_{k, \ell}, \phi_{k, \ell}\right)= \\
& \quad=\frac{1}{T}\left[\int_{0}^{T} s_{k}\left(t-\tau_{k, \ell}\right) s_{\ell}(t) d t\right] \cos \left(\phi_{k}-\dot{\phi}_{\ell}\right),
\end{aligned}
$$

com $\phi_{k} k$-ésima fase da portadora recebida. A variância da componente ruido total, condicionada à $\mathrm{k}$-ésima amplitude, é dada por:

$$
\begin{aligned}
& \operatorname{Var}\left[C_{i+1} \mid A_{k}\right]=\chi_{i+1}= \\
& = \begin{cases}\frac{1}{N} \sum_{k=i+2}^{K^{-}} A_{k}^{2}+\frac{N_{0}}{T}+\frac{1}{N} \sum_{j=1}^{i} \chi_{j} & \text { Sínc. } \\
\underbrace{\frac{1}{3 N} \sum_{k=i+2}^{K} A_{k}^{2}}_{\text {Var. Us. Não-Cancel }}+\underbrace{\frac{N_{0}}{T}}_{\text {Var. Ruido }}+\underbrace{\frac{1}{3 N} \sum_{j=1}^{i} l_{j}}_{\text {Var. Cancel. Imperf }} & \text { Assińnc. }\end{cases}
\end{aligned}
$$

A relação Sinal-Ruido ainda condicionada à $k$-ésima amplitude, para o caso síncrono, será:

$$
\begin{aligned}
S N R_{i+1}= & \frac{\frac{1}{4} A_{i+1}^{2}}{\frac{1}{4} \chi_{i+1}}= \\
& =\frac{A_{i+1}^{2}}{\frac{1}{N} \sum_{k=i+2}^{T} A_{k}^{2}+\frac{N_{0}}{T}+\frac{1}{N} \sum_{j=1}^{i} \chi_{j}} .
\end{aligned}
$$

Admitindo-se aproximação Gaussiana [11] para o ruído total $C_{i+1}$ com média zero e variância $\chi_{i+1}$ resulta, finalmente, a probabilidade de erro de bit $\left(P_{\epsilon}\right)$ para o $i$-ésimo cancelamento sucessivo condicionada às amplitudes:

$$
P_{e}^{i+1}=Q\left(\sqrt{\frac{A_{i+1}^{2}}{\chi_{i+1}}}\right)=Q\left(\sqrt{S_{-} \backslash R_{i-1}}\right) .
$$

Correlações médias (sobre $n$ bitsı na estimação das energias. Pode-se mostrar que em um SIC a variância do ruído total na estimativa das amplitudes decresce de $\mathfrak{n}^{-1}$. supondo-se correlações independentes bit-a-bit: portanto terse-á aumento no desempenho em termos de $P_{e}$ quando se empregam valores de correlaçôes médias sob n bits. Assim, a variância do ruído na variavel de decisăo após o j-ésimo cancelamento para o caso sincron: a assíncrono, respectiva- mente, será:

$$
E\left[\chi_{i+1}\right]=\left\{\begin{array}{l}
\frac{1}{N} \sum_{k=i+2}^{K} E\left[A_{k}^{2}\right]+\frac{N_{0}}{T}+\frac{1}{N \cdot n} \sum_{j=1}^{i} \lambda_{j} \\
\underbrace{\frac{1}{3 N} \sum_{k=i+2}^{K} E\left[A_{k}^{2}\right]}_{\text {Var. Us. Não-Cancel }}+\underbrace{\frac{N_{0}}{T}}_{\text {Var. Ruído }}+\underbrace{\frac{1}{3 N \cdot n} \sum_{j=1}^{i} \chi_{j}}_{\text {Var. Cancel. Imperf }},
\end{array}\right.
$$

com $\mathfrak{n}=$ número de bits utilizados na média. Este procedimento é necessário quando em ambiente com desvanecimento multipercurso Rayleigh.

Caso sejam utilizadas estimativas para as potências dos sinais, ao invés de correlações, no procedimento de ordenação de usuários em um SIC, deve-se ter acurácia da ordem de $3 \mathrm{~dB}$ (em relação à potência real) no processo de estimação das potências a fim de obter $P_{e}$ compativel com aquele resultante do procedimento de ordenação via correlações com $\mathfrak{n}=1$ bit. Se forem tomadas correlações médias sobre $\mathfrak{n}=10$ bits, a acurácia necessária para as estimativas de potência torna-se mais restritiva ainda, da ordem de $1 \mathrm{~dB}$.

\subsection{ASSOCIAÇÃO DE SIC E MUD LINEAR}

Estruturas mais complexas para o cancelamento de interferência foram propostas. onde basicamente troca-se o primeiro estágio Convencional com banco de correlatores da Figura 2 por um MUD linear. Por exemplo, o Descorrelacionador Adaptativo proposto em Chen e Roy [12] é empregado na obtenção de um SIC, Figura 3. O primeiro estágio Descorrelacionador é empregado para estimar o bit do usuário de maior potência recebida. O sinal demodulado deste usuário é regenerado e subtraído do sinal recebido original. O segundo estágio Descorrelacionador emprega este sinal para detectar o próximo usuário de maior potência, cuja influência também é subtraída do sinal agregado resultante da etapa anterior. Cancelamentos sucessivos sāo realizados, respeitando a ordem decrescente das potências recebidas, até que todos os usuários sejam detectados. Quando forem garantidos boa sincronização e conhecimento das sequiências de espalhamento, obter-se-á significativo aumento de desempenho em canal AWGN. O desempenho será muito próximo ao limite single-user garantindo-se controle perfeito de potência $(N F R=0)$. Mesmo com intenso efeito near-far, o detector será robusto.

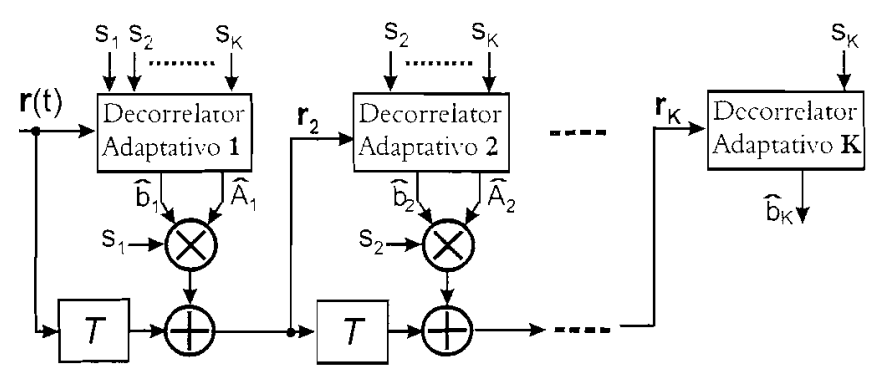

Figura 3. SIC Adaptativo, $K$ usuários. 


\section{DETECTOR PIC}

O detector PIC estima e subtrai. paralelamente, todas as MAI para cada usuário, Figura 4. O primeiro estágio é essencialmente um receptor convencional, composto por um banco de correlatores, produzindo estimativas para os sinais de todos os usuários, $\left\{\widehat{\mathcal{S}}_{1}^{(1)}(t) . \widehat{\mathcal{S}}_{2}^{(1)}(t) \ldots \ldots \widehat{\mathcal{S}}_{\bar{K}}^{(1)}(t)\right\}$; a única diferença é que a decisão de bit não é feita neste ponto. No $2^{\mathrm{O}}$ estágio, as estimativas são então subtraídas do sinal recebido. $r(t)$. restando um sinal residual. Passa-se o resultado por um 20 banco de filtros casados. Cada estágio PIC introduz atraso de $T$ ( 1 bit) no sinal recebido, $r(t)$. e nas amplitudes, $A_{i}$. Este processo pode ser repetido, gerando múltiplos estágios. Em um PIC, pode-se mostrar que a complexidade por símbolo demodulado é linear com relação ao número total de usuários. $\mathcal{O}\left(\hbar^{-}\right)$, enquanto mantém desempenho próximo ao do receptor MUD Ótimo para a maioria dos casos práticos de interesse [1].

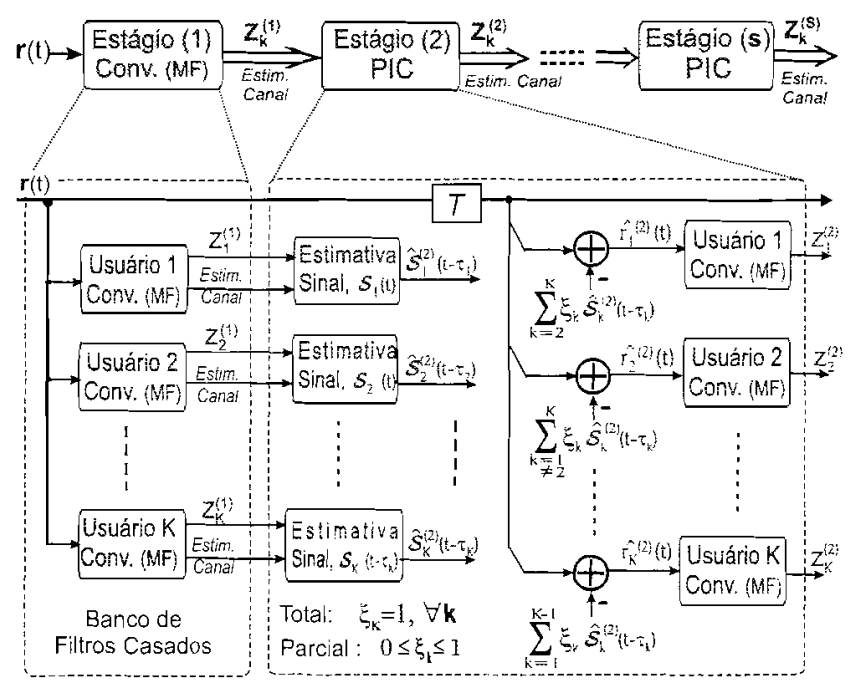

Figura 4. PIC Total (Clássico) e Parcial, $K$ usuários assíncronos e $s$ estágios.

Denomina-se PIC Clássico à estrutura receptora multiusuário com ocorrência de etapas de cancelamento de interferência paralelo no 20 estágio e posteriores, se houver, precedido(s) por um banco de filtros casados (banco de correlatores) às sequiências de espalhamento de cada usuário. Quando houver a tentativa de cancelamento total dos interferentes no $2^{\circ}$ estágio e seguintes o cancelador é denominado PIC Total; por sua vez, quando o cancelamento dos interferentes for escalonado (fator $0<\xi \leq 1$ ), o receptor subtrativo é denominado PIC Parcial. Finalmente, quando não for possível obter estimativas confiáveis para os parâmetros de canal de todos os usuários ativos, pode-se realizar o cancelamento apenas dos usuários com estimativas confiáveis, tratando os demais simplesmente como ruído. A esta estratégia denomina-se PIC Seletivo [13]. Recentemente, inúmeras variações para o detector PIC foram propostas:

1. primeiro estágio: receptor RAKE ou Descorrelacionador ou MMSE, em versões fixas e adaptativast:

${ }^{+}$Canais com desvanecinzento multipercurso e/ou interferência intercelu-
2. cancelamento parcial da MAI em cada estágio, com coeficientes fixos ${ }^{5}$ [14], [15] e adaptativos ${ }^{6}$ [16], resultando no aumento total de cancelamento em cada estágio;

3. decisão abrupta (HD-PIC) [6]: emprego de bits já detectados na saída de um estágio a fim de aumentar o desempenho dos bits remanescentes no mesmo estágio:

4. combinação linear das saídas de decisores suaves (SDPIC) de diferentes estágios;

Analisa-se a seguir o comportamento de um receptor PIC Clássico Total e Parcial em termos de suas estatísticas de decisão, Figura 4, considerando canal AWGN e sequiências aleatórias (Rndz). Evidencia-se a existência de um termo polarização que reduz a média da estatística de decisão $E\left[Z_{i}^{(s)}\right]$ à saída dos estágios canceladores, sendo esta redução proporcional ao carregamento do sistema [17]: sistemas altamente carregados serão mais afetados pelas estimativas polarizadas, terão mais erros nas decisões finais dos bits e, portanto, piores desempenhos.

\subsection{PIC TOTAL CLÁSSICO}

Cada um dos $H^{*}$ usuários transmite um conjunto de dados binários, $\left\{b_{k . i}\right\}$. espalhados pela sequiência de código $s_{k}(t)$, sendo ambas variáveis identicamente independente (i.i.d). $\mathrm{O}$ ganho de processamento definido por $N=\frac{T}{T_{c}}$ identifica adoção de código curto. O sinal A-CDMA recebido em banda base pode ser expresso por:

$$
r(t)=\sum_{k=1}^{K} \underbrace{\sqrt{P_{k}} b_{k}\left(t-\tau_{k}\right) s_{k}\left(t-\tau_{k}\right) e^{j \phi_{k}}}_{\mathcal{S}_{k}(t)}+n(t)
$$

As estimativas das amplitudes dos sinais recebidos, obtidas no $1^{\circ}$ estágio, são empregadas no $2^{\circ}$ estágio na reconstrução dos sinais de todos os usuários, $\widehat{\mathcal{S}}_{k}^{(1)}(t)$, necessária ao cancelamento simultâneo dos interferentes de um determinado usuário

\subsubsection{PRIMEIRO ESTÁGIO: CONVENCIONAL}

Supondo-se que o receptor obtém perfeito sincronismo em relação a todos os usuários presentes em um sistema unicelu$\operatorname{lar}^{7}$ : o sinal recebido é correlacionado a uma cópia da forma de onda de espalhamento, $s_{k}\left(t-\tau_{k}\right)$. Normalizando-se os resultados do valor da correlação assim obtidos por $T$ resulta na estatística de decisão no $1^{0}$ estágio ${ }^{8}$, i-ésimo bit do $\mathrm{k}-$ ésimo usuário:

$$
Z_{k, i}^{(1)}=\frac{1}{T} \int_{i T \perp \tau_{k}}^{(i+1) T+\tau_{k}} \operatorname{Re}\left\{r(t) s_{k}\left(t-\tau_{k}\right) e^{-j \phi_{k}}\right\} d t .
$$

\footnotetext{
5 Distintos ou iguais para todos os usuários.
}

${ }^{6}$ Coeficientes são atualizados periodicamente, baseado em algun critério de estimação de confiabilidade de cada sinal de usuário recebido.

Conhecimento e identificação de todas as seqüēncias de espalhamento e respectiros atrasos de propagação. $\tau_{k}$.

sA nomalização da estatística de decisão por $\mathrm{T}$ remove a dependência em relação à duração de bit. simplificando as análises subsequentes. 
com $\operatorname{Re}\{\}=$. operador parte real de um número complexo. Admitindo-se o $1^{\circ}$ usuário como o de interesse, a métrica de decisão em (9) resulta:

$$
Z_{1, i}^{(1)}=\underbrace{U_{1}}_{\text {Us. Desejado }}+\underbrace{\sum_{k=2}^{K} \mathcal{S}_{k}^{(1)} s_{1}(t) e^{-j o_{1}}}_{\text {MAI, } \mathcal{I}_{1}^{(1)}}+\underbrace{n}_{\text {Ruido }} .
$$

Reescrevendo as estatísticas de decisão do estágio inicial, equação (9), em termos de correlações cruzadas par, $R$ e ímpar, $\breve{R}$, respectivamente, tem-se:

$$
\begin{aligned}
& Z_{1 . i}^{(1)}=\underbrace{\sqrt{P_{1}} b_{1, i}}_{\text {Us. Desejado }}+\underbrace{n}_{\text {Rúdo }}+ \\
& +\underbrace{\sum_{\ell=2}^{K} \sqrt{P_{\ell}} \cos \left(\dot{\phi}_{\ell}-\phi_{1}\right)\left[b_{\ell . i-1} R_{\ell .1}(\tau)+b_{\ell . i} \breve{R}_{\ell .1}(\tau)\right]}_{\text {MAI.I.I }} .
\end{aligned}
$$

A capacidade de exclusão da MAI no filtro casado é determinada pelo ganho de processamento e pela potência relativa do usuário de interesse em relação à dos interferentes. As três componentes na métrica de decisão do $1^{\circ}$ estágio são variáveis aleatórias estatisticamente independentes. As médias e variâncias destas componentes são resultados bem estabelecidos na literatura. A média e a variância total para a estatística de decisão deste estágio, condicionada ao i-ésimo bit transmitido, serão dadas respectivamente por:

$$
\begin{gathered}
E\left[Z_{1 . i}^{(1)} \mid b_{1 . i}\right]=\sqrt{P_{1}} b_{1 . i} \\
\operatorname{Var}\left[Z_{1 . i}^{(1)} \mid b_{1 . i}\right]=\frac{1}{3 N} \sum_{k=2}^{F_{i}} P_{k}+\frac{N_{0}}{2 T},
\end{gathered}
$$

com a variância total composta pelas parcelas das variâncias da MAI e AWGN. A equação (12) indica que a métrica de decisão para o $1^{\circ}$ estágio é composta por estimativas não polarizadas das amplitudes do sinal do usuário de interesse. Finalmente, a expressão da taxa de erro de bit (BER), bem conhecida, para sistema A-CDMA convencional (MF) com modulação BPSK, admitindo-se aproximação Gaussiana para a MAI [11], pode ser escrita como:

$$
\begin{aligned}
B E R^{(1)} & =Q\left(\sqrt{\frac{\left(E\left[Z_{1 . i}^{(1)} \mid b_{1 . i}\right]\right)^{2}}{\operatorname{Var}\left[Z_{1 . i}^{(1)} \mid b_{1 . i}\right]}}\right) \\
& =Q\left(\left[\frac{N_{0}}{2 E_{b_{1}}}+\frac{1}{3 N} \frac{\sum_{k=2}^{K} P_{k}}{P_{1}}\right]^{-\frac{1}{2}}\right)
\end{aligned}
$$

\subsubsection{SEGUNDO ESTÁGIO: CANCELAMENTO PA- RALELO}

O 2ำ estágio reconstroi o sinal transmitido a partir de estimativas da MAI, posteriormente canceladas. Neste processo de reconstrução, a métrica de decisão do $1^{\circ}$ estágio é empregada como medida das amplitudes de primeira ordem para cada sinal transmitido. Assim, considerando média de conjunto, para um dado bit transmitido, a métrica de decisão do $1^{\varrho}$ estágio é igual à amplitude do sinal transmitido de um dado usuário. Portanto, torna-se imediato a construção de um estimador não polarizado para cada usuário com os respectivos bit e amplitude transmitidos, $\widehat{A}_{k} \widehat{b}_{k, i}$, dado por:

$$
\widehat{A}_{k} b_{k, i}=Z_{k, i}^{(1)}
$$

A partir desta estimativa é possível proceder à reconstrução do sinal transmitido de cada usuário (estimativas de primeira ordem), com seus respectivos atrasos admitidos conhecidos:

$$
\begin{aligned}
& \hat{\mathcal{S}}_{k}^{(2)}\left(t-\tau_{k}\right)= \\
& =\sum_{i=-\infty}^{\infty} \widehat{A_{k} b_{k . i}} p_{T}\left(t-\tau_{k}-i T\right) s_{k}\left(t-\tau_{k}\right) e^{j \phi_{k}}= \\
& =\sum_{i=-\infty}^{\infty} Z_{k, i}^{(1)} p_{T}\left(t-\tau_{k}-i T\right) s_{k}\left(t-\tau_{k}\right) e^{j \phi_{k}} .
\end{aligned}
$$

$\operatorname{com} p_{T}(t)$ sendo a formatação de pulso, suposta retangular.

Após a reconstrução de todos os sinais, o cancelamento de interferência Total é implementado pela subtração das estimativas dos sinais dos usuários do sinal recebido, formando um novo sinal recebido reconstituído para cada usuário. Para o k-ésimo usuário. resulta

$$
\widehat{r}_{k}^{(2)}(t)=r(t)-\sum_{\substack{j=1 \\ j \neq k}}^{K} \widehat{\mathcal{S}}_{j}^{(2)}\left(t-\tau_{j}\right)
$$

A efetividade da operação de cancelamento é resultante do grau de acurácia obtida com os sinais da MAI reconstruída.

Cada estimativa de sinal transmitido, $\widehat{\mathcal{S}}_{k}^{(2)}$. torna-se estimativa não polarizada do correspondente sinal transmitido, isto é, a média destas estimativas é o próprio sinal transmitido:

$$
E\left[\hat{\mathcal{S}}_{k}^{(2)}\left(t-\tau_{k}\right)\right]=\mathcal{S}_{k}\left(t-\tau_{k}\right)
$$

No entanto, apesar das médias de conjunto para as estimativas de MAI em (19) serem iguais aos sinais transmitidos verdadeiros, o desempenho do receptor pode ser afetado caso estas estimativas de MAI oscilarem significativamente em torno da média, medida através da variância da MAI reconstituída.

Finalmente, a estatística de decisão para o estágio PIC, após $\widehat{r}_{k}^{(2)}(t)$ passar por um banco de correlatores idênticos ao do $1^{\circ}$ estágio, será:

$$
Z_{i, i}^{(2)}=\frac{1}{T} \int_{i T+\tau_{k}}^{(i+1) T+\tau_{k}} \operatorname{Re}\left\{\widehat{r}_{k}^{(2)}(t) s_{k}\left(t-\tau_{k}\right) e^{-j \phi_{k}}\right\} d t
$$

Após a subtração, caso as estimativas de atraso, fase e de amplitude sejam perfeitas, garante-se a total eliminação da MAI. Nos casos práticos de interesse sempre existirá MAI residual devido à introdução de erros nas estimativas desses parâmetros. Assim, um novo estágio subtrativo paralelo pode 
ser implementado a fim de reduzir o termo da MAI residual. Note que o procedimento de cancelamento subtrativo pode ser repetido inúmeras vezes; porém, a parte substancial do aumento de desempenho é obtido com o 2ำ estágio. Melhoria adicional de desempenho é cada vez menor com o aumento do número de estágios, $s$, uma vez que existe limite para desempenho imposto pelo ganho de processamento do sistema, impedindo separação ainda maior do sinal desejado em relação à MAI.

Desenvolvendo-se uma expressão para a métrica do $2^{\circ}$ estágio em termos da métrica do $1^{\circ}$ estágio e das correlações cruzadas resulta, para o primeiro usuário, de (20) e admitindo-se sem perda de generalidade $\tau_{1}=0$ :

$$
\begin{aligned}
& Z_{1 . i}^{(2)}=\underbrace{Z_{1 . i}^{(1)}}_{\text {10 estágio }}- \\
& -\underbrace{\sum_{\ell=2}^{K} \cos \left(\phi_{\ell}-\phi_{1}\right)\left[Z_{1 . i-1}^{(1)} R_{\ell .1}(\tau)+Z_{1 . i}^{(1)} \breve{R}_{\ell .1}(\tau)\right]}_{\text {Cancelamento de Incerterència }}
\end{aligned}
$$

Substituindo a métrica de decisão do primeiro estágio, na forma de (11), em (21) notar-se-á que a estatística de decisão para o $2^{\circ}$ estágio depende das estimativas das amplitudes, das correlações cruzadas par e ímpar e das fases das portadoras (sistemas coerentes) de todos os usuários ativos. Finalmente, tomando-se a média para a métrica de decisão à saída do $2^{\circ}$ estágio, condicionada ao $i$-ésimo bit transmitido pelo usuário de interesse, $b_{1 . i}$. resultarão três termos [17], cujo termo relativo à MAI conterá alguns produtos de cossenos quadrados, resultando em média distinta de zero:

$$
\begin{aligned}
& E\left[Z_{1 . i}^{(2)} \mid b_{1 . i}\right]=\sqrt{P_{1}} b_{1 . i}- \\
& -E\left[\sqrt{P_{1}} \sum_{\ell=2}^{K} \cos ^{2}\left(\phi_{\ell}-\phi_{1}\right) b_{1 . i}\left(R_{\ell .1}^{2}(\tau)+\hat{R}_{\ell .1}^{2}(\tau)\right)\right] \\
& =\sqrt{P_{1}} b_{1 . i}-\sqrt{P_{1}} b_{1 . i} E \underbrace{\left[\sum_{\ell=2}^{K} \cos ^{2}\left(o_{\ell}-O_{1}\right)\right]}_{=\frac{1}{2}\left(K^{-}-1\right)} \times \\
& \times \underbrace{E\left[R_{\hat{\ell} .1}^{2}(\tau)+\hat{R}_{\hat{\ell} .1}^{2}(\tau)\right]}_{=\frac{2}{3.2}}: \\
& E\left[Z_{1 . i}^{(2)} \mid b_{1 . i}\right]=\underbrace{\sqrt{P_{1}} b_{1 . i}}_{\text {Ampl. Estim }}-\underbrace{\frac{1}{3 \pi} \sqrt{P_{1}} b_{1 . i}(\kappa-1)}_{\text {Terno Polarizacão }} \\
& =\sqrt{P_{1}} b_{1 . i}\left[1-\frac{(\hbar-1)}{3 .}\right] \text {. }
\end{aligned}
$$

Termo de Polarização A equação (22) revela a existência de um termo de polarizaçấ, proporcional ao carregamento do sistema, $K / N$. Esta polarização na estimativa das amplitudes do sinal no 2o estágio causa desvio da região decisão dos sinais recebidos, resultando em aumento da $P_{\epsilon}^{(2)}$. cuja influência torna-se mais significativa em sistemas altamente carregados. Em algumas situações ${ }^{9}$ pode ocorrer a inversão de desempenho: $P_{e}^{(2)}>P_{e}^{(1)}$ : o estágio cancelador tornase ineficiente devido à existência do termo polarização, piorando o desempenho em relação ao sistema Convencional.

$\mathrm{O}$ efeito danoso do termo de polarização em sistemas altamente carregados pode ser atenuado empregando-se seqüências de espalhamento com grandes $N$. No entanto, sistemas de 3 a Geração necessariamente operam na região de forte carregamento, afetando drasticamente a métrica de decisão: redução de $\approx 30 \%$ para sistemas assíncronos e de $\approx 50 \%$ para síncronos, considerando $K / N=1$.

O PIC Parcial é uma solução que consiste na preservação da estrutura de baixa complexidade do MF no $1^{\circ}$ estágio, responsável pela estimação das estatísticas de decisão, associado à ponderação das estimativas de decisão de MAI para os estágios canceladores na proporção do grau de confiança dos sinais, mantendo-se o requisito de baixa complexidade também para estes estágios [17], [18], [19].

Expressões analíticas aproximadas para a $P_{e}^{(s)}$ em um PIC Clássico com cancelamento total e canal AWGN, considerando aproximação Gaussiana para a MAI, foram dadas em [20]. Os desempenhos para canais assíncronos com e sem efeito near-far, considerando o usuário 1 como o de interesse, resultam, respectivamente:

$$
\begin{aligned}
& P_{\epsilon_{1}}^{(s)}=Q\left(\left[\frac{N_{0}}{2 P_{1} T}\left(\frac{1-\left(\frac{K-1}{3 N}\right)^{s}}{1-\frac{K^{N}-1}{3 N}}\right)+(-1)^{s}+\right.\right. \\
& \left.\left.\left(\frac{1}{3 N}\right)^{s}\left(\frac{(K-1)^{s}-(-1)^{s}}{K^{s}}\left(\frac{\sum_{k=2}^{K^{-}} P_{k}}{P_{1}}+1\right)\right)\right]^{-\frac{1}{2}}\right)
\end{aligned}
$$

$$
P_{e}^{(s)}=Q\left(\left[\frac{N_{0}}{2 P T}\left(\frac{1-\left(\frac{K^{*}-1}{3 N^{*}}\right)^{s}}{1-\frac{K^{*}-1}{3 N^{s}}}\right)+\left(\frac{H-1}{3 N}\right)^{s}\right]^{-\frac{1}{2}}\right)
$$

onde $P_{k}$ é a potência recebida para o k-ésimo usuário; $\Pi^{r}=$ número total de usuários ativos no sistema; $T=$ período de bit; $N=$ ganho de processamento do sistema CDMA e ruído Gaussiano com densidade espectral de potência bilateral igual a $\frac{N_{0}}{2}$. As expressões (23) e (24) resultam em boa aproximação para sistemas com baixos níveis de carregamento $\left(\frac{K}{\Lambda}<2.5 \%\right)$, pois no desenvolvimento dessas expressões admite-se que $Z_{k . i}^{(s)}$ são estimativas não polarizadas para $A_{k} b_{k}$ em cada estágio. Infelizmentente. esta hipótese não é verdadeira; $Z_{k, i}^{(s)}$ será polarizada após o $1^{\mathfrak{O}}$ estágio em um PIC Clássico, como mostra (22).

Em PIC, há um limite para $\frac{E_{b}}{N_{0}}$ obtido a partir da mampulação de (24), abaixo do qual o cancelamento não será mais benéfico, ocorrendo $P_{e}^{(s+1)}>P_{e}^{(s)}$, dado por [20]:

$$
\frac{E_{t}}{N_{0}}>\frac{1}{2}\left(1-\frac{H-1}{3 \Gamma}\right)^{-1} \quad \operatorname{com} \quad \frac{K-1}{3 N}<1 .
$$

\footnotetext{
${ }^{9}$ Sistemas sobrecarregados. $\left(K / \Lambda^{-}>1\right)$ e região de baixas $\frac{E_{0}}{V_{0}}$.
} 
A Figura 5 apresenta $\frac{E_{b}}{N_{0}}$ mínimo para que o cancelamento seja benéfico, nos casos de $N=[15,31.63,127]$. Note que corn o PIC multiestágio é possível obter desempenhos benéficos a cada novo estágio mesmo sob elevadíssimos carregamentos de sistema.

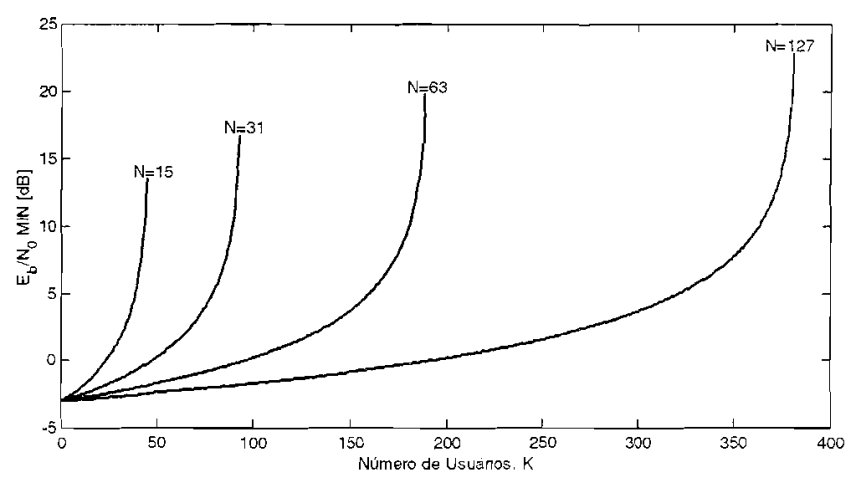

Figura 5. $\frac{E_{k}}{N_{0}}$ mínimo para se obter efetividade no cancelamento de interferência em função do número de usuários, $K$. Diversos ganhos de processamento, $N$. sistema A-CDMA.
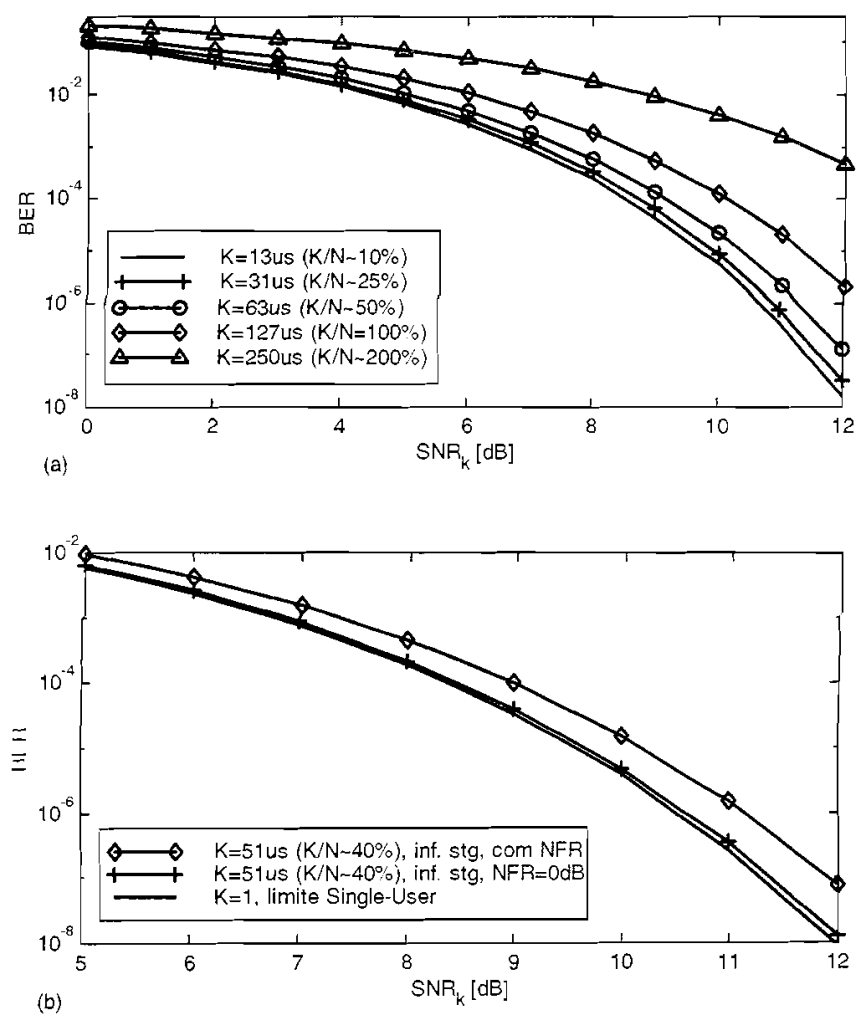

Figura 6. Comportamento Assintótico $(s \rightarrow x)$ para o receptor PIC multiestágio assíncrono, $R n d \approx 12 \bar{\gamma}$. (a) diferentes carregamentos $K / N$; (b) $K=51\left(\frac{K}{N} \approx 40 \%\right)$; pequena degradação devido ao desbalanceamento das potências recebidas.

O comportamento assintótico do receptor multiestágio quando o número de estágios $\mathrm{s} \rightarrow \infty$ e $\frac{K^{*}-1}{3 N}<1$ pode ser obtido a partir de (23), resultando em:

$$
\lim _{s \rightarrow+\infty} P_{e_{1}}^{(s)}=Q\left(\sqrt{\frac{2 P_{1} T}{N_{0}}\left(1-\frac{K-1}{3 N}\right)}\right) .
$$

não dependendo das energias dos usuários interferentes, sendo exclusivamente função do nível de carregamento do sistema e da $\frac{E_{i}}{N_{0}}$ do usuário de interesse. Para o caso de controle perfeito de potência, resulta: $\lim _{s-\infty} P_{e}^{(s)}=$ $Q\left(1.4 \sqrt{\frac{P T}{N_{0}}}\right) \simeq Q\left(\sqrt{2 \frac{E_{i}}{N_{0}}}\right)$. A Figura 6.a mostra o comportamento assintótico para um PIC multiestágio considerando seqüências aleatórias de comprimento $N=127$ ( $R n d z 127$ ) e diferentes carregamentos. Na Figura 6.b são comparados o comportamento assintótico para as situações onde há controle perfeito e desbalanceamento de potência, considerando $K=51$ : para efeito de comparação, mostra-se o himite single-user $(K=1)$. Sob a condição $N F R=0 d B$, o desempenho do PIC multiestágio apresentará uma pequena melhoria em relação à situação de desbalanceamento das potências recebidas, indicando que a estrutura PIC é capaz de operar em ambiente com algum efeito near-far, sem que haja degração apreciável de desempenho.

Melhoria de desempenho para o k-ésimo usuário em um PIC de 1 a 4 estágios canceladores e canal AWGN é apresentada na Figura 7 ; considera-se $N=127, i=37$ usuários com mesma potencia recebida e $N F R=+9 d B$ para metade dos usuários interferentes. São considerados também os casos single user ( $K=1$ ) e quando o número de estágios $s \rightarrow x$. Há um significativo aumento de desempenho quando se passa de 1 para 2 (3) estágios canceladores, no caso de $N F R=0(N F R \neq 0)$ e apenas um pequena melhoria quando se passa de 2 (3) para 3 (4) estágios. A melhoria significativa de desempenho é obtida com poucos estágios. Cancelamentos além de 4 estágios nāo compensam nem o esforço computacional, nem o atraso de processamento adicionais. O maior ganho é obtido na região de alta $\frac{E_{b}}{N_{0}}$, uma vez que melhores estimativas para os sinais podem ser obtidas com a redução do ruído e assim, há melhoria nos cancelamentos, resultando em taxas de erros de bit menores.

A Figura 8 compara o desempenho médio dos detectores Convencional, PIC multiestágio e SIC em dois cenários com desbalanceamento de potência, considerando seqüências Rnd $\approx 32$, canal AWGN, $\frac{E_{b}}{N_{0}}=10 d B$, exato conhecimento dos parâmetros $A, \tau, o$ e correta ordenação das energias recebidas. O detector SIC terá desempenho superior ao PIC em ambiente com desvanecimento e sem controle de potência, uma vez que explora a variação de potência para realizar cancelamento. Já o PIC Total terá desempenho superior ao SIC em canais com controle perfeito de potência. Note que quando houver um maior separação e espalhamento entre os valores das potências recebidas, resultará em melhoria no desempenho do SIC e degração no PIC: compare (a) e (b) da Figura 8. Mesmo assim, o PIC multiestágio resulta em melhor desempenho que o receptor Convencional. No entanto, quando a estimativa de parâmetros não for boa, qualquer operação de cancelamento paralelo, sucessivo ou híbrido (grupo) mostrar-se-á ineficiente.

A Figura 9 apresenta resultados de desempenho médio em função do carregamento do sistema $(\approx 12 \% \mathrm{a} \approx 86 \%)$ para os principais detectores IC e lineares em ambiente com controle perfeito de potência; considera-se sequiências aleatórias de $N=128$ e $\frac{E_{b}}{N_{0}}=10 d B$. Exceto na situação de NFR com potências recebidas bastante espalhadas, o desempenho 
do detector PIC multiestágio ${ }^{10}$ é superior ao do SIC e será sempre melhor que o MMSE, Descorrelacionador e Convencional.
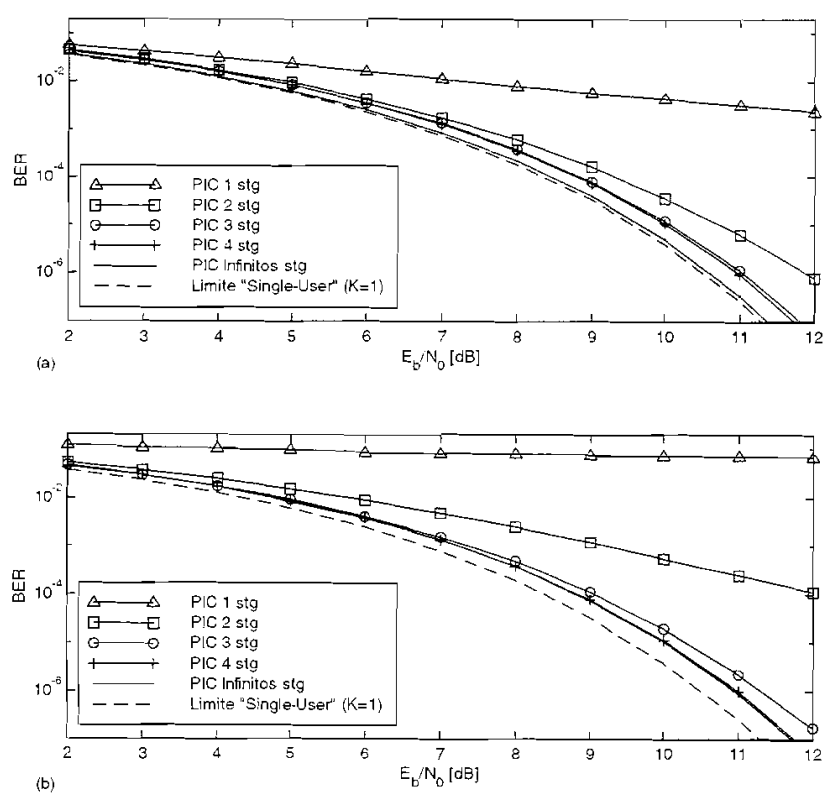

Figura 7. $B E R$ analítico $\times \frac{E_{t}}{\lambda_{0}}$ para PIC assíncrono em canal AWGN, $K^{-}=37$ usuários e $R n d \approx 12 \overline{7}$; (a) controle perfeito de potência (b) metade dos usuários interferentes com $N F R=+9 d B$. São mostrados ainda o comportamento assintótico $(s \rightarrow \infty)$ e o limite single-user.
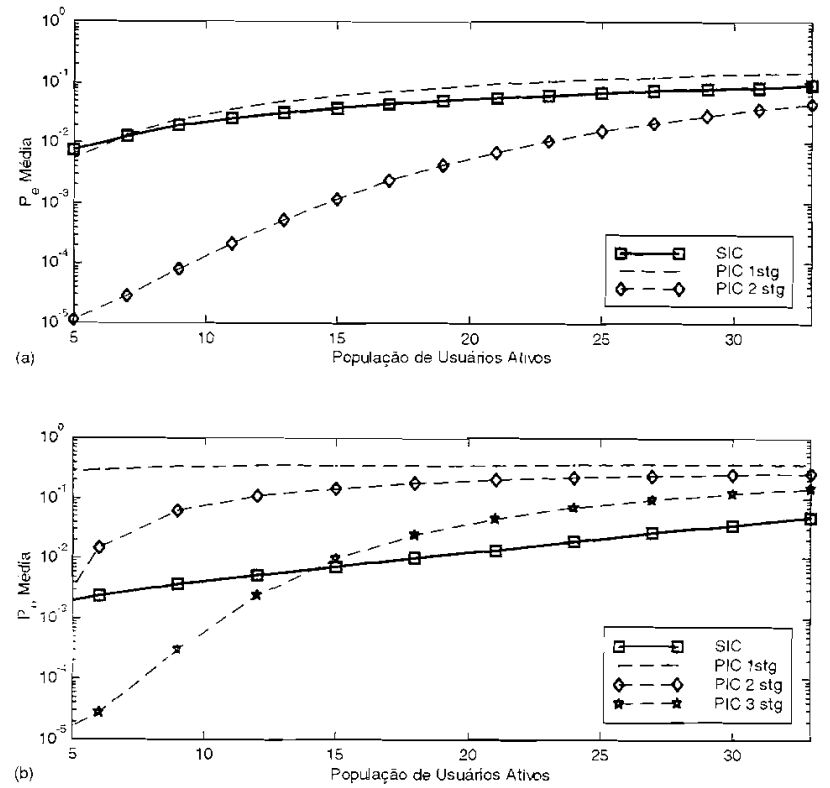

Figura 8. $\overline{B E R}$ para PIC multiestágio e SIC Assíncronos com Rnd $z 32, \frac{E_{b}}{N_{0}}=10 d B$ e efeito Near-Far:(a) metade dos usuários interferentes ativos com potência recebida $10 \mathrm{~dB}$ acima dos demais. (b) $N F R$ distintos com potências separadas de $1 / 2 \mathrm{~dB}$ : para $\mathrm{K}_{\mathrm{max}}=33$ usuários resulta $\backslash F R=9.5$ $8,58.0 \ldots .6 .0-6.5 d B$

As estimativas para a taxa de erro de bit, obtidas na Figura

\footnotetext{
${ }^{10}$ Assumido acurácia nas estimativas dos parânetros atraso. fase e amplitudes dos sinais recebidos
}

7 e em (23), (24), tornam-se otimistas na região de baixas $P_{e}$ e $K / N$ elevados. Considerando esta limitação, técnica mais elaborada incluindo efeitos de segunda ordem da MAI no cálculo da $P_{e}$ foi desenvolvida em [21], permitindo obter previsões de desempenhos mais realistas naqueles casos onde as potências interferentes apresentam distribuição aleatória.

\subsection{PIC PARCIAL CLÁSSICO}

A solução de cancelamento Parcial não elimina a polarização, porém é uma solução de baixíssima complexidade adicional e mostra-se efetiva na redução da taxa de erro de bit. Tal solução preserva o estimador de amplitudes do $1^{\circ}$ estágio (MF) que por sua natureza resulta em métrica de decisão polarizada quando associado a um estágio de cancelamento subtrativo. Esta solução é motivada pela dificuldade de se encontrar estimadores não polarizados de baixa complexidade. Estimadores não polarizados resultam em maior complexidade que as operações de multiplicação e acumulação do filtro casado e possivelmente introduzem não linearidades.

O cancelamento Parcial está baseado no princípio de que estimativas de MAI não confiáveis devem resultar em cancelamentos parciais, resultando na redução da taxa de erro de bit em relação ao caso em que cancelamentos totais são realizados para as estimativas não confiáveis de MAI. Podese então postular que ponderando as estimativas de MAI na proporção de sua confiabilidade, reduzir-se-ão os efeitos da polarização sobre a taxa de erro de bit. Em essência, o PIC ponderado consiste no cancelamento de uma percentagem da MAI, escalonando-se o sinal reconstituído de cada interferente por um fator, denominado SCF (Soft Cancellation Factor), compreendido no intervalo $0 \leq \xi_{k} \leq 1$ [22]. O valor de $\xi_{k}$ depende do grau de confiança da estimativa da MAI e dos parâmetros do sistema: $N, P_{i}$ (equivalente a $\frac{E_{b}}{N_{0}}$ ), $K^{\circ}$ e atrasos $\tau_{k}$. A estrutura de um cancelador de interferência paralelo parcial de um estágio é a mesma do PIC Total, exceto que os cancelamentos no $2^{\circ}$ e demais estágios são ponderados pelos coeficientes $\xi_{k}$. Figura 4. Aplicando-se o princípio de cancelamento escalonado ao PIC Clássico, obtém-se um ganho de desempenho em relação ao PIC Total com aumento de complexidade mínimo [14], [22], [17], [19].

A complexidade de implementação do PIC Parcial torna-se proporcional a $K^{* 2}$. Porém, caso seja possível obter controle perfeito de potência, bastará um único $\mathrm{SCF}$ para todos os usuários, reduzindo-se à complexidade linear, proporcional a $K$. No caso mais geral (efeito near-far), para cada usuário será necessário a estimação de amplitude e obtenção do fator de cancelamento parcial correspondente, $\xi_{k}$.

\subsubsection{RECEPTOR PIC PARCIAL SÍNCRONO}

Considere um sistema S-CDMA ao nível de bit, dispensando a modelagem dos atrasos de propagação dos diversos usuários através do canal. O cancelamento Parcial é obtido escalonando cada uma das estimativas dos sinais reconstruídos. O conjunto de fatores SCF é formado por $\left\{\xi_{k}\right\}$, $k \in\{1.2 \ldots \ldots K\}$ O $1^{\circ}$ estágio é idêntico ao caso do PIC Total: um receptor de conrelação CDMA convencional. As estatísticas de decisão para i-ésimo bit do k-ésimo usuário é dada por (9), tomando-se $\tau_{k}=0$. No $2^{\circ}$ Estágio, a 


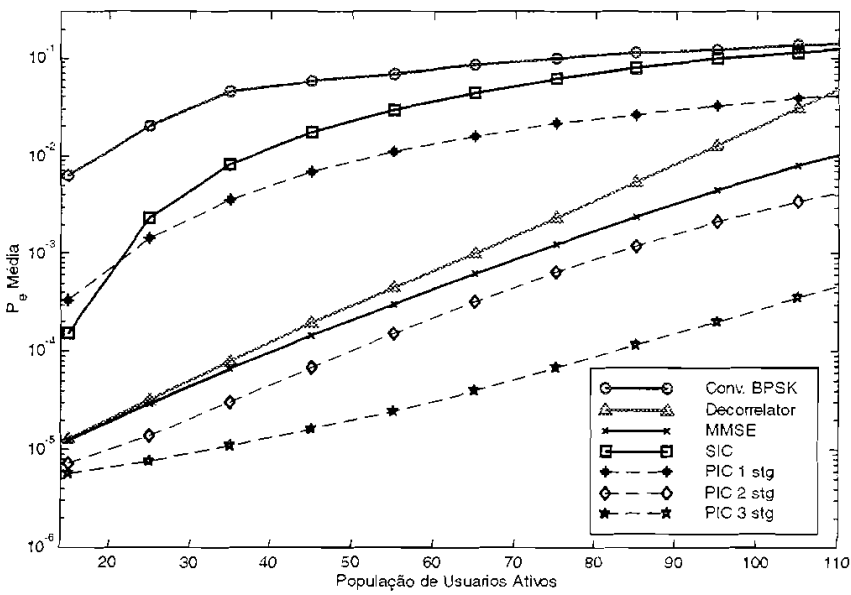

Figura 9. Comparação de desempenho em termos de $\overline{B E R}$ $x$ número de usuários para os detectores SIC, PIC de 1 a 3 estágios, Convencional BPSK, Descorrelacionador e MMSE Síncronos e $N F R=0$. Seqüências $R n d z 128 \mathrm{e} \frac{E_{b}}{N_{0}}=10 \mathrm{~dB}$.

reconstrução do sinal transmitido de cada usuário (estimativas de primeira ordem), sem os atrasos, toma a forma (17). Aqui, atribui-se um fator SCF a cada interferente e procedese à nova reconstrução do sinal recebido, para cada usuário, de acordo com:

$$
\widehat{r}_{k}^{(2)}(t)=r(t)-\sum_{\substack{i=1 \\ r \neq k}}^{K} \xi_{r i} \widehat{\mathcal{S}}_{r i}^{(2)}(t) .
$$

Cada sinal reconstruído através do uso dos fatores SCF alimenta um banco de correlatores idênticos ao do $1^{\circ}$ estágio, Figura 4, a fim de obter um versão mais limpa para o conjunto das estatísticas de decisão, como em (20).

$O$ objetivo consiste em empregar o conjunto de fatores SCF para minimizar a $B E R^{(2)}$; admitindo ainda o $1^{\mathfrak{Q}}$ usuário como o de interesse, deve-se procurar o conjunto $\left\{\xi_{\ell}\right\}, \ell \in$ $\left\{2, \ldots, \Lambda^{-}\right\}$, tal que:

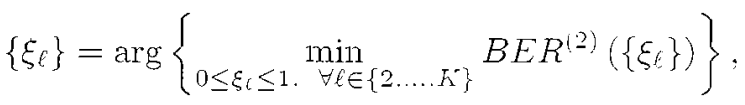

onde $B E R^{(2)}\left(\left\{\xi_{\ell}\right\}\right)$ é defimido como em (14). Para a determinação do conjunto de fatores SCF tal que minimize a $B E R^{(2)}$, deve-se caracterizar a métrica de decisão e analisar o efeito da polarização sob o ponto de vista do cancelamento parcial.

\subsubsection{MÉTRICA E POLARIZAÇÃO NO PIC PAR- CIAL}

A análise da métrica no PIC Parcial pode ser derivada em parte do caso anterior, canal assíncrono. As simplificações consideradas aqui são $\tau_{k}=0$ e portanto as correlações cruzadas pares e ímpares são reduzidas a:

$$
\Gamma_{m . \ell}=\frac{1}{T} \int_{0}^{T} s_{m \ell}(t) s_{\ell}(t) d t=\breve{R}_{\ell . m}(0) .
$$

Primeiro Estágio. Reescrevendo (9) em termos de correlações cruzadas, a estatística de decisão reduz-se a:

$$
Z_{1 . i}^{(1)}=\underbrace{\sqrt{P_{1}} b_{1 . i}}_{\text {Us. Desejado }}+\underbrace{\sum_{\ell=2}^{K} \sqrt{P_{\ell}} b_{\ell . i} \Gamma_{1 . \ell} \cos \left(\phi_{\ell}-\phi_{1}\right)}_{\text {MAI }}+\underbrace{n}_{\text {Ruído }} .
$$

A média e variância para a métrica de decisão do $1^{\circ}$ estágio podem ser calculadas a partir da determinação separada das médias e variâncias das 3 componentes, resultando:

$$
\begin{aligned}
E\left[Z_{1 . i}^{(1)} \mid b_{1 . i}\right] & =\sqrt{P_{1}} b_{1, i} . \\
\operatorname{Var}\left[Z_{1 . i}^{(1)} \mid b_{1 . i}\right] & =\frac{1}{2 N} \sum_{\ell=2}^{K} P_{\ell}+\frac{N_{0}}{2 T} .
\end{aligned}
$$

Variâncias do $1^{\circ}$ estágio - caso Síncrono $\times$ Assíncrono. Comparando-se (32) com (13), observa-se que a variância do 1 o estágio (MF) para o caso síncrono é maior que para o assíncrono, resultando no aumento da taxa de erro de bit. Assim, o $1^{\text {o }}$ estágio Convencional com sinais síncronos ao nível de bit constitui a situação de pior caso para o cálculo de $B E R^{(1)}$

Finalmente, a expressão da taxa de erro de bit, bem conhecida, para sistema S-CDMA Convencional com modulação BPSK pode ser escrita, para o $1^{\circ}$ usuário, como:

$$
B E R_{\text {Sinct }}^{(1)}=Q\left(\left[\frac{N_{0}}{2 E_{b_{1}}}+\frac{1}{2 N} \frac{\sum_{\ell=2}^{K} P_{\ell}}{P_{1}}\right]^{-\frac{1}{2}}\right)
$$

Segundo Estágio. Pode-se obter as estatísticas de decisão do $2^{\circ}$ estágio em termos das estatísticas do $1 \cong$ estágio, das correlações cruzadas e dos fatores SCF, seguindo-se os mesmos passos anteriores até (21), com as devidas simplificações:

$$
Z_{1 . i}^{(2)}=\underbrace{Z_{1 . i}^{(1)}}_{\text {1̊ estágio }}-\underbrace{\sum_{\ell=2}^{K} \xi_{\ell} Z_{1 . i}^{(1)} \Gamma_{\ell .1} \cos \left(\theta_{\ell}-\theta_{1}\right)}_{\text {Cancelamento de Interferéncia com SCF }} .
$$

Substituindo-se a métrica de decisão do $1^{\circ}$ estágio de (30) em (34), pode-se concluir que a estatística de decisão para - 20 estágio ainda dependerá das estimativas das amplitudes, das sequiências de espalhamento de todos os usuários ativos, das fases das portadoras (sistemas coerentes) e das correlações cruzadas.

A média para métrica de decisão à saída do $2^{\circ}$ estágio, condicionada ao i-ésimo bit transmitido pelo usuário de interesse, $b_{1 . i}$. analogamente a (22), ainda contém o termo polarização, porém ponderado pelos fatores SCF [14], [17]:

$$
E\left[Z_{1 . i}^{(2)} \mid b_{1 . i}\right]=\sqrt{P_{1}} b_{1 . i}\left[1-\frac{\sum_{\ell=2}^{K^{r}} \xi_{c}}{2 N}\right]
$$

Para a variância, resulta uma expressão analítica extensa [17], tendo por base o ruído incrementado, $\frac{N_{0}}{2 T}\left[1+\frac{1}{2 N} \sum_{\ell=2}^{K^{2}} \xi_{\ell}^{2}\right]$ e somatórias simples do tipo 
$\frac{1}{2 N} \sum_{\ell=2}^{K_{\ell}} P_{\ell} \xi_{\ell}^{2}$, duplas: $(2 N)^{-2} \sum_{\ell=2}^{K_{i}} \sum_{\substack{m=2 \\ m \neq \ell}}^{K_{l}} \xi_{\ell}^{2} P_{n 2}$ e triplas: $(2 N)^{-3} \sum_{\ell=2}^{K} \sum_{\substack{m=2 \\ m \neq \ell}}^{K} \sum_{\substack{n=2 \\ n \neq m}}^{K} \xi_{\ell} \xi_{n} P_{m}$.

Obs.1. Em geral, a taxa de erro de bit após cancelamento Parcial é menor que antes; a contribuição do ruído na variância total é ampliada devido ao uso do estimador MF no processo de cancelamento. Porém, o processo de cancelamento geralmente remove mais MAI do que adiciona ruído, tornando a variância do $2^{\circ}$ estágio muito menor que a obtida para o $1^{\varrho}$ estágio Convencional (32), indicando que as estimativas das amplitudes no $2^{\circ}$ estágio afastam-se bem menos de suas respectivas médias que no caso do estágio com $\mathrm{MF}$, resultando em menor taxa de erro de bit.

Obs.2. No cancelamento Parcial, a polarização ainda existe. Comparando-se (35) com (22), nota-se a diferença de fator $\frac{1}{2}$ no lugar de $\frac{1}{3}$, devido à mudança de canal assíncrono para síncrono e a somatória dos fatores SCF dos interferentes devido ao cancelamento parcial. Tomando-se o cancelamento Total em canal síncrono ter-se-á:

$$
E\left[Z_{1 . i}^{(2)} \mid b_{1 . i}\right]=\sqrt{P_{1}} b_{1 . i}\left[1-\frac{K^{-}-1}{2 N}\right]
$$

pois $\xi_{\ell}=1$ para todos os interferentes. Portanto no PIC Parcial sempre resultará em uma redução na magnitude do termo polarização, já que $\sum_{\ell=2}^{K} \xi_{\ell}<(K-1)$.

Obs.3. Há uma diferença entre a magnitude da polarização em um canal síncrono e assíncrono para usuários com mesma potência unitária:

$$
\begin{aligned}
\mid \text { Bias Sínc }_{N F R=0} & =\frac{K-1}{2 N}, \\
\mid \text { Bias Assinc }_{N F R=0} & =\frac{K-1}{3 N} .
\end{aligned}
$$

Isto se deve aos valores médios distintos para as correlações cruzadas normalizadas considerando seqüências de espalhamento aleatórias: em canais assíncronos com fases aleatórias este valor é $1 / 3 N^{\circ}$. enquanto que para sistemas síncronos é $1 / 2 N[11]$.

Obs.4. As equações para as médias das estimativas de amplitudes em um estágio PIC Total síncrono (36) e assíncrono (22), indicam que o limitante para o cancelamento de interferência será $K \leq 2 N+1$ usuários síncronos e $K \leq 3 N+1$ usuários assíncronos. (25), Figura 5. Um número de usuários acima destes limitantes causa inversão nas estatísticas de decisão dos dados, resultando em $B E R=0.5$. Tais limitantes são justificados também pelos valores médios distintos das correlações cruzadas.

\subsubsection{INTERPRETAÇÃO DO FATOR DE CANCE- LAMENTO PARCIAL}

A designação do fator SCF ótimo para o k-ésimo usuário, $\xi_{k_{O p t}}$. depende do valor de $N$ : de todas potências recebidas, $P_{i}$; da potência de ruído e dos demais fatores $\mathrm{SCF}, \xi_{i}, i \neq k$.

A partir da expressão da $B E R^{(2)}$, função dos fatores $S C F$, obtém-se o conjunto dos SCF otimizados tal que minimize a taxa de erro. Efetivamente, os fatores $\xi_{0 p t}$ reduzem a polarização na métrica de decisão no $2^{\circ}$ estágio, aumentando o desempenho do PIC. A convegência do fator SCF para cada usuário indica que a $B E R^{(2)}$ assim obtida corresponde ao ponto de mínimo ${ }^{11}$. Adotando-se o $1^{\complement}$ usuário como o de interesse, tem-se a atribuição ótima do SCF para o k-ésimo interferente:

$$
\begin{aligned}
&\left\{\xi_{k}\right\}_{O p t}: \frac{\partial}{\partial \xi_{k}}[\arg (Q(.))]= \\
& \quad=\frac{\partial}{\partial \xi_{k}}\left[\frac{\left(E\left[Z_{1 . i}^{(2)} \mid b_{1 . i}\right]\right)^{2}}{\operatorname{Var}\left[Z_{1 . i}^{(2)} \mid b_{1 . i}\right]}\right]=0,
\end{aligned}
$$

com $k \in\{2,3 \ldots . K\}$, resultando em [17]:

$$
\xi_{k_{O^{t}}}=\frac{\mathcal{A}}{\mathcal{B}}
$$

onde

$$
\begin{gathered}
\mathcal{A}=8 N^{3}\left(P_{k}-\frac{N_{0}}{2 T}\right)-4 N^{2} \frac{N_{0}}{2 T} \sum_{\substack { \ell=2: \ell \neq k \\
\begin{subarray}{c}{\ell=2 \\
\ell \neq k{ \ell = 2 : \ell \neq k \\
\begin{subarray} { c } { \ell = 2 \\
\ell \neq k } }\end{subarray}}^{K} \xi_{\ell}^{2}- \\
\left.-(2 N-1)\left(\sum_{\substack{m=2 \\
m \neq k \cdot \ell}}^{K} P_{m}+2 N P_{\ell}\right)\right] \\
-\sum_{\substack{\ell=2 \\
\ell \neq}}^{K} \sum_{\substack{\ell=2 \\
\ell \neq k}}^{K} \xi_{\ell \neq k}\left[2 P_{k}-P_{\ell}\right]-
\end{gathered}
$$

$$
\begin{aligned}
& \mathcal{B}=8 N^{-3}\left(P_{k}+\frac{N_{0}}{2 T}\right)-4 N^{2} \frac{N_{0}}{2 T} \sum_{\substack{\ell=2 \\
\ell \neq \frac{1}{k}}}^{K^{\prime}} \xi_{\ell}- \\
&-\sum_{\substack{\ell=2 \\
\ell \neq k}}^{K} \xi_{\ell} {\left[P_{1}(7 N-6)+(2 N-1)\left(\sum_{\substack{m=2 \\
n \neq \neq k \ell \ell}}^{K} P_{m}+2 N P_{k}\right)\right] } \\
&-2 N(2 N-1)\left[\sum_{\substack{m=2 \\
m \neq k}}^{K} P_{m}+(6-7 N) P_{1}\right] \cdot(41)
\end{aligned}
$$

Casos limites para $\xi_{O p t}$. Observando-se o comportamento assintótico dos fatore SCF, considerando (39), tem-se:

1. Ganho de processamento infinito $(N \rightarrow \infty)$ :

$$
\lim _{N \rightarrow \infty} \xi_{k}=\frac{P_{k}-\frac{N_{0}}{2 T}}{P_{k}+\frac{N_{0}}{2 T}}
$$

isto é, na situação assintótica quando o sistema tem completa imunidade à MAI $(N \rightarrow \infty), \mathrm{o} \xi_{k}$ dependerá exclusivamente da potência do $k$-ésimo interferente e da potência do AWGN [20].

\footnotetext{
${ }^{11} \mathrm{~A}$ segunda derivada do argumento da função Q(.) em relação a $\xi_{k}$ é
} positiva. 
2. Ganho de processamento e imunidade à MAI infinitos: corresponde a considerar o caso anterior com a hipótese adicional de ausência de ruído, obtém-se um sistema com estimativas perfeitas de MAI:

$$
\lim _{\substack{N \rightarrow \infty \\ N_{0} \rightarrow 0}} \xi_{k}=1
$$

3. Controle perfeito de potência: $P_{k}=P=\frac{E_{b}}{T}, \forall k$. Após algumas passagens em (39), considerando que todos os usuários terão a mesma potência recebida, resulta um mesmo SCF para todos os usuários, determinado por:

$$
\begin{aligned}
& \xi\left(N, K^{2} P\right)_{N F R=0}= \\
& =\frac{\frac{E_{b}}{N_{0}}\left(4 N^{2}-2 N\right)-2 N^{2}}{\frac{E_{b}}{N_{0}}\left[4 N^{2}+2 K^{2}(2 N-1)-3 N-2\right]+2 N^{2}} .
\end{aligned}
$$

uma vez que para as mesmas potências recebidas as estimativas da MAI para todos os usuários apresentarão o mesmo grau de confiança e portanto deverão ter o mesmo valor de escalonamento, $\xi$.

A Figura 10 sintetiza o comportamento do $\left.\xi_{O p t}\right|_{N F R=0}$ para ganho de processamento $N=63, \frac{E_{b}}{N_{0}}$ no intervalo de 0 a $10 \mathrm{~dB}$ e carregamento do sistema entre 0 a $100 \%$. Quanto mais as estimativas de MAI se desviarem de seus valores verdadeiros, devido ao ruído total ${ }^{12}$ ou à presença de outros usuários acessando o canal (maior carregamento do sistema), menor será o valor do fator de cancelamento parcial, indicando que as estimativas de MAI não são confiáveis e portanto não serão totalmente canceladas. Inversamente, a região de maior confiabilidade para as estimativas de MAI será aquela cujo $K^{*} / N$ for muito baixo e simultaneamente baixo ruído total, resultando em fatores SCF próximos à unidade.

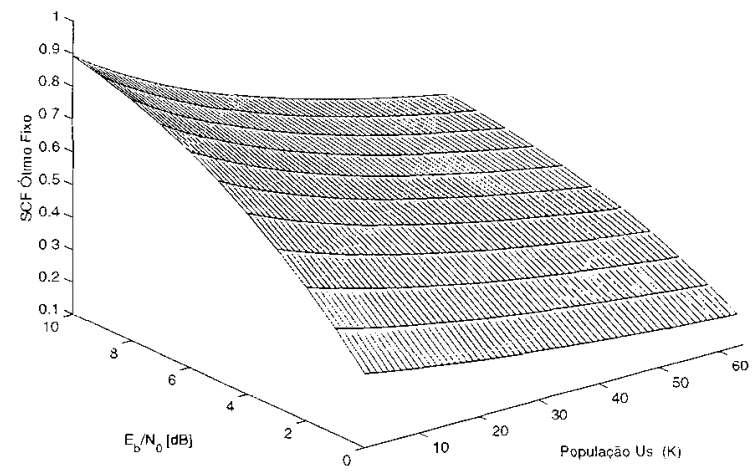

Figura 10. $\xi_{O p t}$ versus número de usuários ativos, $K$ e $\frac{E_{b}}{N_{0}}$, considerando $N=63$ e controle perfeito de potência.

\footnotetext{
${ }^{12} \mathrm{Baixos} \frac{E_{b}}{N_{0}}$ e/ou alta interferência intercelular e/ou usuários não sincronizados.
}

Desempenho PIC Parcial - Controle Perfeito de Potência. Para canal com controle perfeito de potência, a média em (35) e a variância para as estatísticas de decisão do PIC Parcial reduzem-se a:

$$
\begin{gathered}
E\left[Z_{1 . i}^{(2)} \mid b_{1 . i}\right]_{N F R=0}=\sqrt{P_{1}} b_{1 . i}\left(1-\frac{\left(K^{2}-1\right) \xi}{2 N}\right) \\
\operatorname{Var}\left[Z_{1 . i}^{(2)} \mid b_{1 . i}\right]_{N F R=0}=\frac{P N_{0}}{2 E_{b}}\left(1+\frac{(K-1) \xi^{2}}{2 N}\right)+ \\
+\frac{P(K-1)}{2 N}\left[1+\left(1+\frac{9}{4 N}-\frac{3}{2 N^{2}}\right) \xi^{2}-2 \xi-\right. \\
\left.-\frac{(K-1) \xi^{2}}{2 N}\right]+\frac{P(K-1)\left(K^{2}-2\right) \xi}{2 N^{2}} \\
\cdot\left[2 \xi-1+\frac{(K-3)^{2} \xi}{4 N}\right] .
\end{gathered}
$$

A Figura 11.a compara as médias das estimativas das amplitudes degradadas para o $2^{\circ}$ estágio de um PIC Total e Parcial em função do carregamento de um sistema S-CDMA com controle perfeito de potência e Rnd $\approx 63$. Note que a redução na degração da média aplicando-se os valores $\xi_{O p t}$ é cada vez maior à medida que o sistema torna-se mais carregado. Como já visto, a degradação nas estimativas ocorre devido ao termo de polarização, inerente ao estimador de amplitudes baseado no MF.

A taxa de erro de bit mínima em uma estrutura PIC Parcial é obtida com a designação ótima dos coeficientes SCF. A Figura 11.b apresenta o desempenho de um PIC de um estágio com $\xi_{O p t}$ em função do carregamento. para um sistema SCDMA e os mesmos parâmetros anteriores. Mostra-se que o desempenho do PIC Parcial Otimizado é superior ao PIC Parcial com fatores SCF não otimizados.

Os desempenhos de um PIC de um estágio em função de $\frac{E_{b}}{N_{0}}$ para diferentes $\xi$ são comparados na Figura 12.a: são considerados PIC Total $(\xi=1)$, PIC Parcial $\operatorname{com} \xi=0,3$, $\xi=0.8$ não otimizados e PIC Parcial Otimizado, com o conjunto de fatores $\xi_{o p t}\left(\frac{E_{b}}{k_{0}}\right)$ mostrados na Figura 12.b. Consideram-se os parâmetros $K=31$ usuários e $N=63$ em um sistema S-CDMA em canal AWGN.

Simplificação no projeto do receptor PIC Parcial objetivando a manutenção da complexidade de implementação próxima à do PIC Total consiste na atribuição de um único $\xi$ (fixo). Foi mostrado em [18] que um fator de cancelamento $\xi=0.5$ no $1^{\circ}$ estágio cancelador de um PIC Parcial resulta em bom compromisso, atingindo melhoria significativa de desempenho para carregamentos acima de $60 \%$.

\subsubsection{MODIFICAÇÕES NO PIC PARCIAL}

Pode-se ampliar a análise de desempenho $\times$ complexidade em PIC considerando ambientes mais realistas e/ou melhorando ainda mais o desempenho obtido com um PIC Parcial em relação ao PIC Total a partir das seguntes modificações:

- desempenho do PIC Parcial em ambientes mais realistas: canais assíncronos com desvanecimento multipercurso: 

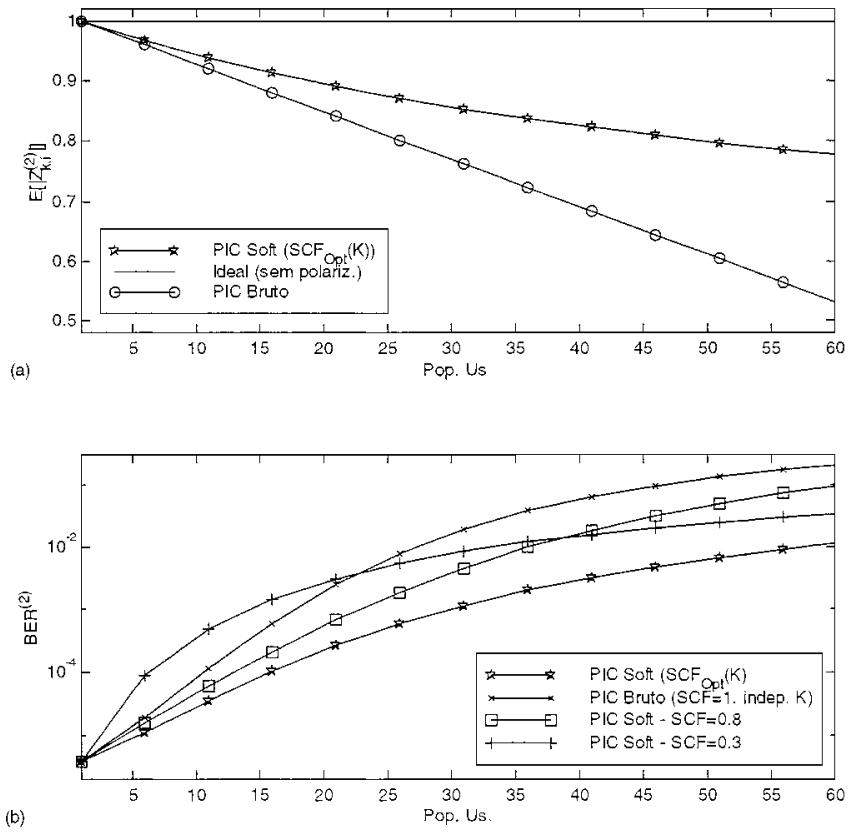

Figura 11. PIC Parcial. $V F R=0 \mathrm{~dB}$, S-CDMA, Rnd 63 e $\frac{E_{b}}{N_{0}}=10 \mathrm{~dB}$. (a) Efeito do termo polarização sobre $E\left[Z_{k, i}^{(2)}\right] . \quad$ (b) $B E R^{(2)} \operatorname{com} \xi_{o p t}\left(I^{-}\right) \times$carregamento do sistema. Comparação com fatores de cancelamento não otimizados.

- desempenho com erros nas estimativas dos atrasos, fases [23] e potências de ruído e sinal ${ }^{13}$;

- obtenção de estimadores de amplitudes não polarizados: resulta em melhoria de desempenho às custas de aumento de complexidade;

- outras estratégias de atribuição de um único ${ }^{1+}$ SCF para todos os usuários tal que a diferença entre a taxa de erro de bit obtida e a taxa de erro de bit ótima seja minimizada;

- alternativamente, atribuição de coeficientes SCF distintos para cada usuário de um modo adaptativo [16].

\section{DETECTOR DDF}

O Detector subtrativo de decisão realimentada do tipo Zero-Forcing, ZF-DF (Zero-Forcing Decision FeedBack) é também denominado Descorrelacionador de Decisão Realimentada, DDF (Decorrelating Decision FeedBack) [24], [25]. Em [7], Duel-Hallen propõe uma estrutura para o Descorrelacionador Linear multiusuário com decisão de bits realimentada para CDMA síncrono, uma vez que utiliza as diferenças de energia dos usuários, resultando em desempenho melhorado em relação ao Descorrelacionador Linear: [8] é a versão assíncrona CDMA do trabalho anterior. Tipicamente, o DDF realiza duas operações: pré-processamento linear e detecção SIC. A operação linear descorrelaciona

\footnotetext{
${ }^{13}$ Assumiu-se aqui conhecimento perfeito destes parâmetros.

${ }^{14}$ Visando a redução da complexidade de implementação
}

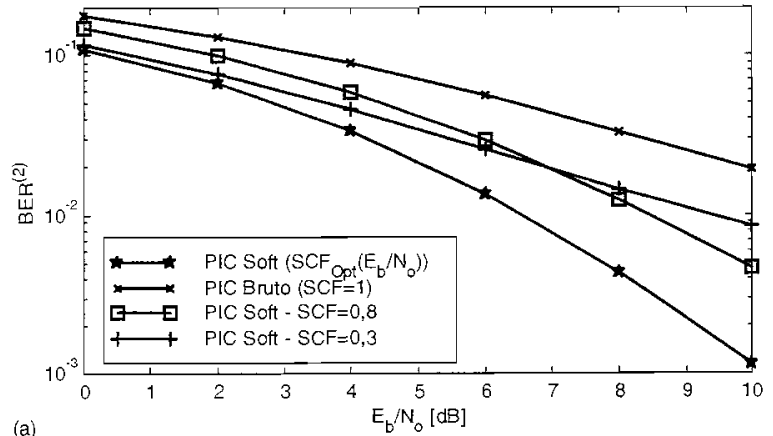

(a)

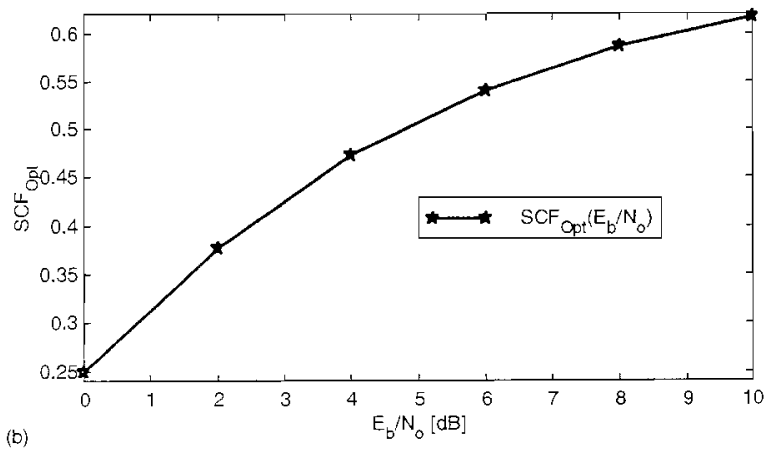

Figura 12. Desempenho do PIC, S-CDMA com $N=63$ e $K^{*}=31$ (carregamento $\approx 50 \%$ ) com distintos fatores $\xi$. (a) Taxa erro de bit após um estágio PIC, considerando distintos fatores SCF. (b) $\xi_{O p t}$ em função $\frac{E_{b}}{N_{0}}$.

parcialmente os usuários sem aumentar o ruído. A última operação, decide e subtrai a interferência de cada usuário, uma a uma, em ordem decrescente da intensidade do sinal. Admitindo-se que todas as decisões passadas sejam corretas, o DDF elimina por completo toda a MAI e maximiza a SNR. Isto é análogo ao equalizador ZF-DF empregado no combate a ISI.

O DDF está baseado em um modelo de canal com AWGN. Otimizam-se os filtros direto e reverso a fim de obter completa eliminação da MAI, admitindo-se que os dados realimentados foram previa e corretamente detectados. Decisões para todos os usuários são feitas em ordem decrescente das energias recebidas. O receptor, para cada usuário, realiza a combinação linear das saídas amostradas de uma matriz de filtros casados com as decisões de todos os usuários interferentes mais fortes que o usuário a ser detectado, Figura 13. Portanto, para o usuário com maior energia não há realimentação, sendo seu desempenho equivalente ao obtido com o Descorrelacionador Linear. Assim, no esquema DDF, os usuários mais fracos serão os maiores beneficiados. O usuário mais fraco, por utilizar as decisões de todos os outros usuários, idealmente ${ }^{15}$, atinge o mesmo desempenho de um sistema single-user sem interferentes.

Inicialmente admite-se que o receptor conheça as energias dos usuários e estas energias estão ordenadas da seguinte forma: $E_{1} \geq E_{2} \geq \ldots \geq E_{K}$. Adicionalmente, supõese aqui um sistema S-CDMA com $K$ usuários. Um banco de filtros casados às respectivas seqüências dos assinantes é seguido por amostradores à taxa de bit, resultando no vetor

\footnotetext{
${ }^{15}$ Quando todos os símbolos realimentados forem corretos.
} 
saída em tempo discreto, Figura 13:

$$
\mathrm{y}=\mathrm{RAb}+\mathrm{z} .
$$

com $\mathbf{R}=$ matriz de correlação, dimensão $K \times K^{-}: \mathbf{A}=$ matriz diagonal das amplitudes: $\mathrm{z}=$ vetor ruído Gaussiano com matriz de autocorrelação, dimensão $K \times \kappa^{-} \mathbf{R}(\mathbf{z})=\sigma^{2} \mathbf{R}$. $\operatorname{com} R(\mathbf{z})_{i, j}=E\left[z_{i}, z_{j}\right]$.

No Descorrelacionador linear, a forma de recuperar o vetor de bit de dados $\mathrm{b}$ dado o vetor de saída $\mathbf{y}$, consiste em aplicar a matriz de filtro $R^{-1}$ seguida por um conjunto de dispositivos de decisão [1]. A saída da matriz de filtro será simplesmente:

$$
\widehat{\mathbf{y}}=\mathrm{Ab}+\widehat{\mathrm{z}} .
$$

com a matriz de autocorrelação do vetor ruído Gaussiano, $\mathbf{R}(\widetilde{\mathbf{z}})=\sigma^{2} \mathbf{R}^{-1}$. A probabilidade de erro de bit para o $\mathrm{k}$ ésimo usuário é calculada como:

$$
P_{k}^{\text {Dec_Sync }}=Q\left(\frac{A_{k}}{\sqrt{\sigma^{2}\left[\mathbf{R}^{-1}\right]_{k k}}}\right) .
$$

Um filtro capaz de adaptar canais com ruído Gaussiano ${ }^{16}$ (Noise-Whitening Filter) pode ser obtido fatorando-se a matriz definida positiva de correlação, R. dimensão $K \times K$. através de:

$$
\mathbf{R}=\mathbf{F}^{\top} \mathbf{F} .
$$

com $\mathbf{F}$ uma matriz triangular inferior ${ }^{17}$, obtida via algoritmo de decomposicão de Cholesky [7], [26], [27]. Assim, se um filtro com resposta $\left(\mathbf{F}^{T}\right)^{-1}$ for aplicado às saídas de um banco de filtros casados às respectivas sequiências dos assinantes, Figura 13. e seguido por amostradores à taxa de bit, $R$, resultará em um modelo discreto de ruído branco

$$
\breve{\mathbf{y}}=\mathrm{FAb}+\mathbf{n} .
$$

obtendo-se o branqueamento do ruído (Whitened Matched Filters), com $\mathbf{n}=$ vetor ruído Gaussiano branco com matriz de covariância do ruído igual a $\sigma^{2} \mathbf{I}=\frac{x_{0}}{2} \mathbf{I}$.

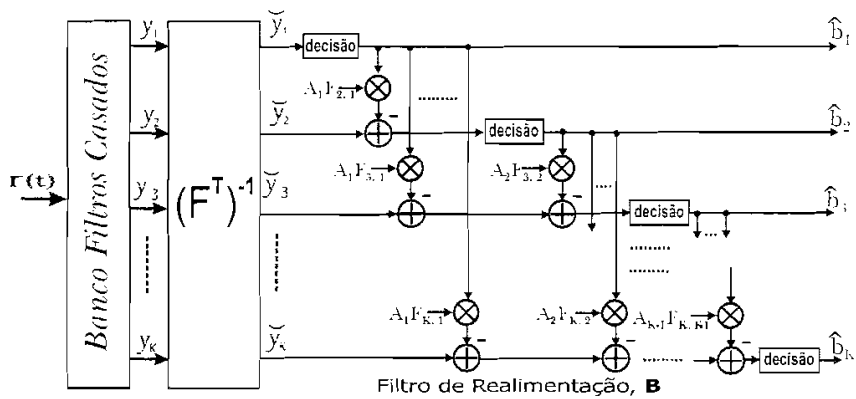

Figura 13. Receptor não linear DDF, $K$ usuários síncronos.

Os bits de dados do modelo de canal com AWGN são parcialmente descorrelacionados, e isto pode ser comprovado pelo fato de $\mathbf{F}$ ser triangular inferior. A saída para o bit 1 do $1^{\circ}$ usuário não contém MAI. A saída para o bit $I$ do $2^{\circ}$ usuário contém MAI apenas do bit 1 do $1^{\circ}$ usuário e está por completo descorrelacionado dos demais usuários. Similarmente,

\footnotetext{
${ }^{16}$ Porém não AWGN.

${ }^{17}$ Isto é. $F_{k, i}=0$ se $k<i, \operatorname{com} F_{k, i} \circ(k, i)$-ésimo elemento de $\mathbf{F}$.
}

a saída do $k$-ésimo usuário para o intervalo de bit $i$ estará por completo descorrelacionado dos usuários $k+1, k+2, \ldots, k$, para o intervalo $i$ : e de todos os bits para intervalos de tempo futuros. O detector DDF emprega detecção SIC a fim de explorar a descorrelação parcial dos bits em um modelo de ruído branco. A saída do decisor suave para o bit $l$ do $I^{\circ}$ usuário, o qual está livre por completo de MAI, é usada para regenerar e cancelar as demais saídas com MAI, resultando em uma saída suave para o bit $l$ do segundo usuário, também livre por completo de MAI. Para cada nova iteração, a MAI contribui para que um bit adicional (o bit anteriormente descorrelacionado) seja regenerado e cancelado, gerando um novo bit descorrelacionado.

Antes da obtenção e aplicação da $\left(\mathrm{F}^{\top}\right)^{-1}$, a fim de obter o modelo AWGN, os usuários devem ser ordenados de acordo com sua intensidade de sinal. O detetor DDF da Figura 13 manipula um bit por intervalo de tempo, una vez que supõe canal síncrono: portanto, a dimensão dos vetores e a ordem de F são reduzidos a $K$. Admitindo-se adicionalmente estimativa perfeita para $\mathbf{F}$ e para as amplitudes recebidas, pode-se demodular todos os usuários sequiencialmente.

A $k$-ésima componente de $\mathbf{y}$ (51) será dada por

$$
\breve{y}_{k}=\underbrace{F_{k, k} A_{k} b_{k}}_{\text {us. interesse }}+\underbrace{\sum_{i=1}^{k-1} F_{k, i} A_{i} b_{i}}_{\text {MAI }}+\underbrace{n_{k}}_{\text {AWGN }} .
$$

e uma vez que (52) não contém o termo de interferência multiusuário para o usuário mais forte, realiza-se $I^{\underline{Q}}$ a decisão para o usuário com maior energia recebida: $\widehat{b}_{1}=\operatorname{sgn}\left(\bar{y}_{1}\right)$. A interferência multiusuário para o segundo usuário mais forte será $F_{2.1} A_{1} b_{1}$. E uma vez que neste ponto do processo de detecção a decisão de bit para o Iํ usuário está disponível. pode-se realimentar este bit a fim de obter a estimativa de símbolo para o segundo usuário. A segunda decisão será então: $\widehat{b}_{2}=\operatorname{sgn}\left(\breve{y}_{2}-F_{2.1} A_{1} \widehat{b}_{1}\right)$. Para o késimo usuário em ordem decrescente de energia recebida, a interferência multiusuário depende dos $i$ usuários mais fortes, $\operatorname{com} i=1.2 \ldots k-1$. As decisões para estes usuários foram feitas, podendo ser usadas na reconstrução do sinal interferente (termo realimentado): a estimativa para o $k$-ésimo usuário será dada por [7]:

$$
\begin{aligned}
& \widehat{b}_{k}=\operatorname{sgn}\left(\breve{y}_{k}-\sum_{i=1}^{k-1} F_{k, i} A_{i} \widehat{b}_{i}\right) \\
& =\operatorname{sgn}\left(F_{k, k} A_{k} b_{k}+\sum_{i=1}^{k-1} F_{k, i} A_{i}\left(b_{i}-\widehat{b}_{i}\right)+n_{k}\right) .
\end{aligned}
$$

Assim, o DDF é caracterizado pelo filtro de realimentação:

$$
\mathrm{B}=\left(\mathbf{F}-\mathbf{F}^{d}\right) \mathrm{A}
$$

onde $\mathbf{F}^{d}=$ matriz diagonal obtida de $\mathbf{F}$ fazendo-se todos os elementos não pertencentes à diagonal principal iguais a zero. $\mathrm{O}$ filtro é alimentado pelo vetor de decisão, $\widehat{\mathbf{b}}$. $\mathrm{O}$ vetor de entrada para o conjunto de dispositivos de decisão é

$$
\breve{y}-\mathbf{B b}=\mathbf{F}^{\mathrm{d}} \mathbf{A b}+\left(\mathbf{F}-\mathbf{F}^{\mathrm{d}}\right) \mathbf{A}(\mathbf{b}-\widehat{b})+\mathbf{n} .
$$


e uma vez que $B$ é triangular inferior com zeros na diagonal principal, apenas as decisões anteriores $\left(\widehat{b}_{k-1} \cdot \widehat{b}_{k-2} \ldots \widehat{b}_{1}\right)$ são necessárias para formar a entrada para o k-ésimo dispositivo de decisão.

De (53), conclui-se que a relação sinal-ruído para o $\mathrm{k}$ ésimo usuário do DDF, à entrada do dispositivo de decisão, sob a hipótese das decisões anteriores estarem corretas, será simplesmente

$$
\mathrm{SNR}_{\mathrm{k}}=\frac{\left(\mathrm{F}_{\mathrm{k} . \mathrm{k}} \mathrm{A}_{\mathrm{k}}\right)^{2}}{\sigma^{2}} .
$$

As principais desvantagens e limitações do DDF são:

- cômputo da decomposição de Cholesky;

- inversão da matriz $\mathrm{F}^{\top}$ :

- estimativa para as amplitudes dos sinais recebidos.

Caso as saídas dos decisores suaves do Descorrelacionador sejam utilizadas para estimar as amplitudes, o DDF será equivalente ao Descorrelacionador. Se as estimativas das amplitudes forem mais confiáveis que aquelas produzidas pelo Descorrelacionador, o DDF resultará em melhor desempenho.

\subsection{EQUIVALÊNCIA DDF - CANCELADOR DE RUÍDO}

Pode-se mostrar que o DDF é equivalente a um detector de cancelamento de ruído obtido a partir do modelo de tempo discreto em (48); uma vez que a inversa da matriz de correlações $\mathbf{R}^{-1}=\left(\mathbf{F}^{T} \mathbf{F}\right)^{-1}=\mathbf{F}^{-1}\left(\mathbf{F}^{T}\right)^{-1}$, (48) pode ser reescrita como:

$$
\begin{aligned}
\widetilde{y} & =R^{-1} \mathbf{R A b}+\mathbf{R}^{-1} \mathbf{z} \\
& =\mathrm{Ab}+\mathbf{F}^{-1} \underbrace{\left(\mathbf{F}^{T}\right)^{-1}}_{\text {filtro Whitened }} \mathbf{z} \\
\widetilde{\mathbf{y}} & =\mathrm{Ab}+\mathbf{F}^{-1} \mathbf{n} .
\end{aligned}
$$

$\operatorname{com} \mathbf{n}=$ vetor ruído $\mathrm{AWGN}$ em (51). Como $\mathrm{F}^{-1}$ é triangular inferior, ou seja $\tilde{y}_{k}=A_{k} b_{k}+\sum_{i=1}^{k}(F)_{k . i}^{-1} n_{i}$. podese construir um detector que emprega decisôes anteriores da sequência de ruido, $\hat{n}_{1}, \hat{n}_{2}, \ldots, \hat{n}_{k-1}$ a fim de reduzir a variância do ruído na $k$-ésima componente de (48) ou (57). Assim, a k-ésima decisão de bit deste detector será dada por:

$$
\begin{aligned}
& \hat{b}_{k}=\operatorname{sgn}\left(\tilde{b}_{k}\right) \\
& \hat{b}_{k}=\operatorname{sgn}\left(\tilde{y}_{k}-\sum_{i=1}^{k-1}\left(F^{-1}\right)_{k, i} \hat{n}_{i}\right) .
\end{aligned}
$$

após o que se obtém a k-ésima estimativa de ruído: $\widehat{n}_{k}=$ $F_{k, k}\left(\tilde{b}_{k}-A_{k} \hat{b}_{k}\right)$.

\subsection{DESEMPENHO PARA O DDF}

Admitindo-se que as energias dos usuários sejam estimadas corretamente, a taxa de erro de bit para o DDF é obtida diretamente de (56):

$$
\bar{P}_{k}^{D D F-S y n c}=Q\left(\frac{F_{k, k} A_{k}}{\sigma}\right) .
$$

É imediato mostrar que $F_{k, k}^{2} \geq \frac{1}{\left(\mathbf{R}^{-2}\right)_{k, k}}$. Observe que para o usuário mais forte, $\left(k_{i}=1\right) \cdot F_{1.1}^{2}=\frac{1}{\left(\bar{R}^{-1}\right)_{1.1}}$ e então a estimativa para probabilidade de erro de bit dada por (60) tornase a probabilidade de erro de bit final, uma vez que o receptor para o usuário mais forte não utiliza realimentação. Portanto para o usuário mais forte vale $P_{1}^{D D F}=P_{1}^{D e c}$. Para usuários mais fracos, $(k=2,3, \ldots, K)$ uma melhoria no desempenho é obtida no DDF. Para o usuário mais fraco, $F_{K}^{2} K=1$ resultando em um desempenho idêntico ao obtido no sistema single-user, $P_{e}^{S U D}=Q(A / \sigma)$.

Em um DDF, a $P_{e}$ exata é obtida tomando-se a média condicional da probabilidade de erro de bit para um dado padrão de erros para os usuários mais fortes, $1,2, \ldots, k-1$, sobre todos os padrões possíveis de erros:

$P_{k}^{D D F}=\frac{E_{\Delta b_{1} \ldots . \Delta b_{h-1}}}{2} Q\left(\frac{F_{k, k} A_{k}+\sum_{i=1}^{k-1} F_{k, i} A_{i} \Delta b_{i}}{\sigma}\right)$

com o padrão de erro para o i-ésimo usuário dado por $\Delta b_{i}=\left(b_{i}-\hat{b}_{i}\right)$. Considerando um sistema com 2 usuários e matriz de correlação $\mathbf{R}=\left(\begin{array}{ll}1 & r \\ r & 1\end{array}\right)$, resultam: $\mathbf{R}^{-1}=$ $\left(\begin{array}{cc}\frac{1}{1-r^{2}} & \frac{r}{-1+r^{2}} \\ \frac{r}{-1+r^{2}} & \frac{1}{1-r^{2}}\end{array}\right)$ e $\mathbf{F}=\left(\begin{array}{cc}\sqrt{1-r^{2}} & 0 \\ r & 1\end{array}\right)$. A taxa de erro de bit para o $1^{\mathrm{O}}$ usuário é a mesma do Descorrelacionador clássico: $P_{1}^{D D F}=P_{1}^{D e c o r}=Q\left(A_{1} \sqrt{\left(1-r^{2}\right)} / \sigma\right)$. Assim, a estimativa de decisão para o segundo usuário será:

$$
\begin{aligned}
\widehat{b}_{2} & =\operatorname{sgn}\left[F_{2.2} A_{2} b_{2}+F_{2.1} A_{1}\left(b_{1}-\widehat{b}_{1}\right)+n_{2}\right] \\
& =\operatorname{sgn}\left[A_{2} b_{2}+r A_{1}\left(b_{1}-\widehat{b}_{1}\right)+n_{2}\right] .
\end{aligned}
$$

Tomando-se a média sobre todos os possíveis valores assumidos por $b_{1}-\widehat{b}_{1}$, deriva-se a taxa de erro de bit para o usuário mais fraco como:

$$
\begin{aligned}
P_{2}^{D D F_{S} \text { Sync }} & =\left(1-P_{1}\right) Q\left(\frac{A_{2}}{\sigma}\right)+ \\
+ & \frac{P_{1}}{2}\left[Q\left(\frac{A_{2}+2 r A_{1}}{\sigma}\right)+Q\left(\frac{A_{2}-2 r A_{1}}{\sigma}\right)\right] .
\end{aligned}
$$

Supondo que a energia do segundo usuário $A_{2}$ esteja fixa e a do $1^{\circ}$ cresça; $P_{1}$ torna-se menor e então o $1^{\circ}$ termo em (62) será dominante. A taxa de erro de bit do usuário mais fraco aproximar-se-á do limite single-user. Portanto, o DDF é atrativo para ambiente com efeito near-far Considerando os parâmetros para um S-CDMA com 2 usuários: $r=0,7$ e $\mathrm{SNR}_{2}=\frac{E_{2}}{\sigma^{2}}=11 d B$ (fixo), resulta no desempenho da Figura 14, para o usuário mais fraco, considerando o DDF, Descorrelacionador linear e limite single-user. Note que o desempenho do DDF aproxima-se do limite single-user à medida em que a energia do usuário mais forte cresce.

Caso os usuários não estejam ordenados corretamente, isto é, $A_{1}<A_{2}$. o segundo e terceiro termo em (62) serão significativos (propagação de erros) e a realimentação não será benéfica. De fato, para uma dada faixa de valores de $A_{1}$, a $P^{D D F-S y n c}>P^{\text {Decor_Sync }}(\approx$ entre $-\bar{i} \mathbf{a}-1 d B$, Figura 


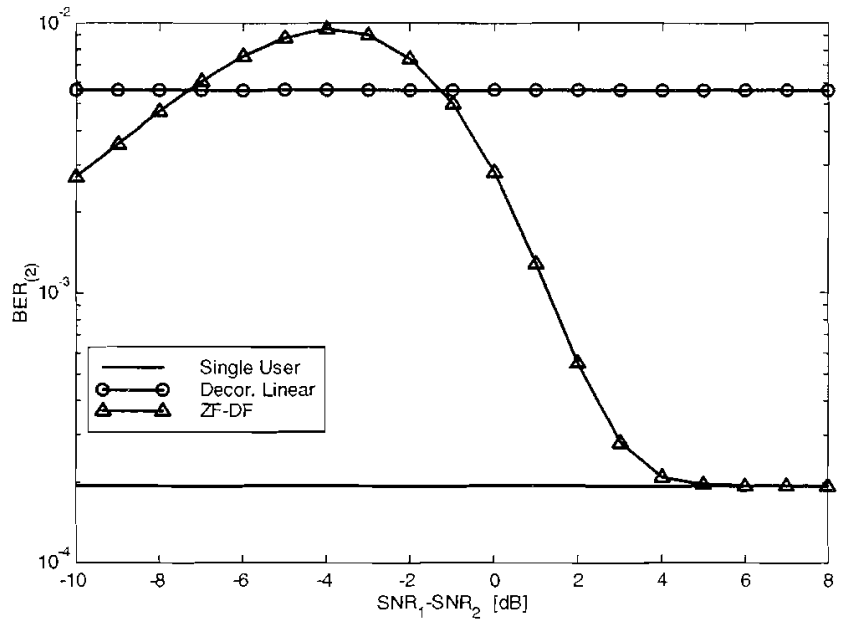

Figura 14. BER para o $2^{\circ}$ usuário em um DDF com $K=$ 2 usuários, $r=0.7$ e $S N R_{2}=11 d B$. Comparação com Descorrelacionador Clássico e limite Single-User: Estimação perfeita das energias e atrasos.

14). Finalmente, tomando-se uma faixa de valores para $A_{1}$ ainda menor $(\lesssim-7 d B$,), o DDF novamente resulta em melhor desempenho que o Descorrelacionador clássico. No entanto, o ganho neste região não é significativo em relação ao Descorrelacionador linear e portanto para pequenos valores de $A_{1}$ a melhor escolha obviamente é o detector Convencional [1].

\section{ERROS NAS ESTIMATIVAS DE $\tau_{K^{r}}, \phi_{K}$ E $A_{K^{-}}$}

Muitos dos receptores MUD resistentes ao efeito nearfar necessitam conhecer uma quantidade substancial de parâmetros: número de usuários; respectivas sequiências de espalhamento; potências recebidas; fases das portadoras e atrasos de propagação. O número de usuários e as seqüiencias estão disponíveis facilmente; porém, os demais parâmetros devem ser estimados. Grande parte dos MUD apresentados na literatura consideram conhecimento perfeito das matrizes correlação cruzada, $\mathbf{R}$, e energias dos usuários, E. Na prática, estas quantidades devem ser estimadas. Ainda, considerar estimação perfeita dos parâmetros atrasos de propagação, fases das portadoras (sincronismo) e amplitudes (ganhos do canal) dos usuários pode conduzir a uma incorreta comparação entre detectores, uma vez que alguns detectores não utilizam todas estas informações. Por exemplo, o Descorrelacionador não depende das energias dos usuários para operar corretamente e o Convencional necessita conhecer apenas a sequiência de espalhamento do usuário de interesse.

\subsection{ROBUSTEZ DOS DETECTORES MUD}

Qual o desempenho resultante quando as estimativas dos parâmetros $\tau_{k}, \phi_{k}$ e $A_{k}$ contém erros? Quais entre os detectores são inerentemente robustos (ou menos sensíveis) ao erros dos parâmetros de canal? [28] mostrou que o Descorrelacionador manterá sua característica de resistência ao efeito near- far apenas para pequenos erros nas estimativas dos atrasos de propagação, tipicamente $2 \%$ de $T_{c}$. No entanto, [9] e [23] analisando o detector PIC concluiram que este cancelador apresenta certa robustez aos erros de sincronização. Mesma conclusão chegaram Holtzman e Cheng [29] com relação ao SIC. No entanto, estes trabalhos compararam algoritmos distintos, utilizaram distintos modelos para descrever os erros, e finalmente utilizaram um conjunto de parâmetros de sistema diferentes entre si.

Em [30] tentou-se uma comparação unificada para os principais MUD lineares e não-lineares (Convencional. Descorrelacionador, MMSE, SIC e PIC). Investigou-se o efeito dos erros das estimativas dos atrasos de propagação, $\tau_{k}$, e das fases das portadoras, $\phi_{k}$ sobre o desempenho. Substituiu-se os dois parâmetros por suas respectivas estimativas, $\widehat{\tau}_{k}$ e $\widehat{\phi}_{k}$. No caso dos MUD lineares, a partir das estimativas $\widehat{\tau}_{k}$ e $\widehat{\phi}_{k}$ obtém-se uma estimativa para a matriz de correlação, $\widehat{\mathbf{R}}$. Admitiu-se um modelo simplificador para os erros, a fim de tornar a modelagem e as simulações mais tratáveis: todos os erros são constantes para um bloco de dados; todos os usuários terão igualmente os maiores erros (pior caso) em seus parâmetros e estimativas para todos os $K$ usuários serão dadas por:

$$
\begin{aligned}
& \widehat{T}_{k}=\tau_{k}+\Delta T_{c} . \\
& \widehat{\phi}_{k}=\phi_{k}+\delta_{\phi} .
\end{aligned}
$$

com $\Delta T_{c}=$ erro de atraso de sincronismo relativo; $\delta_{\phi}=$ erro de fase absoluto para a portadora. Atrasos $\tau_{k}$ e fases $\phi_{k}$ são uniformente distribuídos em $[0, T]$ e $[0,2 \pi]$, respectivamente.

Resultados de [30] indicaram que todos os detectores MLD lineares e não lineares analisados são severamente afetados pelos erros nas estimativas de atraso e fase da portadora, experimentando quase todos a mesma degradação. Para erros moderados de fase, $\delta_{\phi} \leq 20^{\circ}$, o desempenho não é tão afetado quanto ao experimentado quando ocorrem erros de estimação de atraso acima de $25 \%$ de $T_{c}$. A principal conclusão é que nenhum desses detectores será resistente ao efeito near-far quando se introduz quantidade razoável de erros nas estimativas dos parâmetros atraso $\left(\Delta T_{c}>10 \%\right)$ e fase da portadora $\left(\delta_{\infty}>20^{\circ}\right)$. Mesmo assim, os MUD ainda terão desempenho muito superior em relação ao detector Convencional.

No processo de detecção, erros nas estimativas de atraso resultam na perda de parte da energia do sinal recebido, já que as formas de onda das seqüências de espalhamento empregadas no processo de correlação tornam-se "descasadas"; uma vez que o atraso não é perfeitamente conhecido no receptor, não é possível reconstruir o sinal em um IC e portanto as estimativas da MAI não serão exatas. Estimativas de atrasos dos usuários e das fases das portadoras (sistemas coerentes) em receptores PIC introduzem ruído no processo de cancelamento dos interferentes, degradando o desempenho global do sistema. O emprego de médias reduz a variância dos parâmetros estimados [18].

As Figuras 15 e 16 mostram o impacto no desempenho PIC Clássico Total multiestágio devido aos erros nas estimativas dos atrasos. Na Figura 15 são considerados o desempenho para o PIC de 1 a 3 estágios com carregamento de $0 \mathrm{a} \approx 80 \%$ com estimativas perfeitas e erros de atrasos de $10 \%$ de $T_{c}$ em 


\section{Taufik Abrão e Paul Jean E. Jeszensky Detectores Multiusuários para DS/CDMA - Canceladores de Interferência}

todos os sinais recebidos. A robustez do PIC multiestágio contra erros nas estimativas de atraso é mostrada na Figura 16. Considera-se carregamento da ordem de $33 \%$. Note que erros de até $10 \%$ a $15 \%$ de $T_{c}$ ainda são suportáveis em um PIC multiestágio sem que haja degradação significativa na taxa de erro de bit.

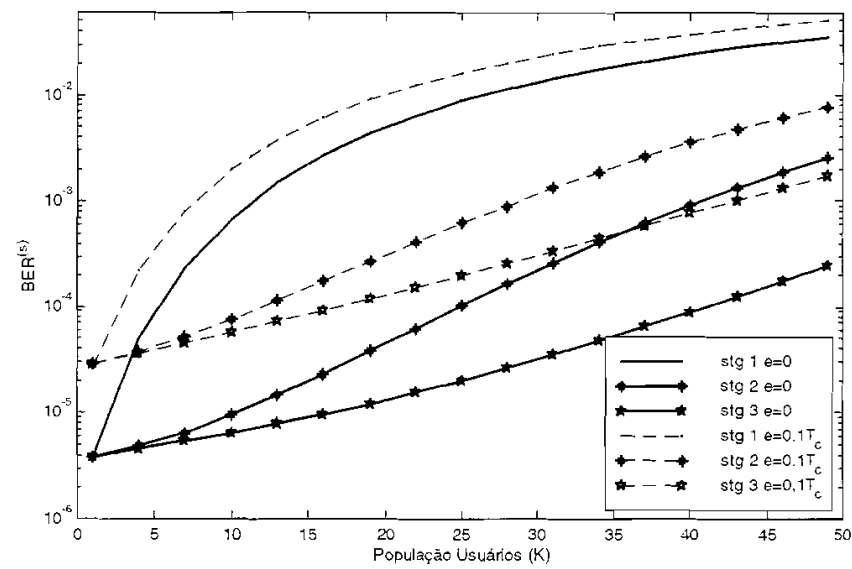

Figura 15. Capacidade para o detector PIC Total multiestágio considerando todos os usuários afetados pelo mesmo erro nas estimativas de atrasos $=0,1 T_{c}$. Rnd $z 63, \frac{E_{b}}{N_{0}}=10$ $\mathrm{dB}$ e $N F R=0$.

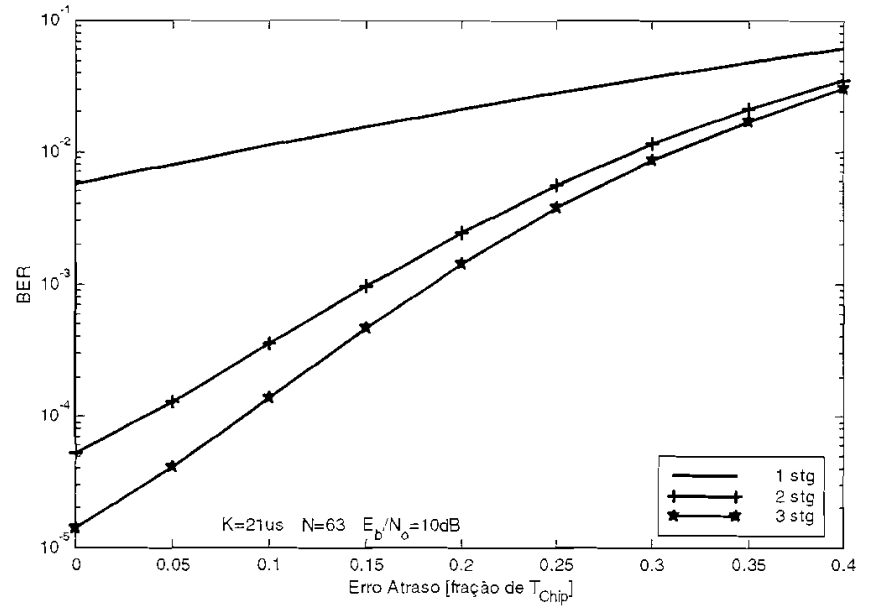

Figura 16. Impacto no desempenho de um PIC Total multiestágio em função dos erros nas estimativas de $\tau$. Considerase Rnd $\approx 63, \frac{K^{2}}{N} \approx 33 \%$ e $\frac{E_{b}}{N_{0}}=10 d B$. Todos os usuários experimentam o mesmo erro nas estimativas.

\subsubsection{ESTIMAÇÃO E ATUALIZAÇÃO DAS ENER- GIAS EM DDF E IC}

Em um ambiente CDMA variável no tempo, geralmente o receptor desconhece as energias e portanto é necessário estimar e atualizar as amplitudes recebidas para todos os usuários. Considere o detector não linear DDF da seção 4. Supondo que uma única transmissão ocorra, dadas as saídas descorrelacionadas do filtro whitened (57), é razoável estimar a amplitude para o k-ésimo usuário como $\widehat{A}_{k}=\left|\tilde{y}_{k}\right|$. Isto implica que a k-ésima decisão de ruído será $\widehat{n}_{k}=0$, resultando em um detector que não cancela o ruído, sendo equivalente ao Descorrelacionador. Se as energias variarem lenta- mente é possível melhorar o método de estimação tomandose a média dos valores absolutos das $N$ saídas anteriores; assim, a k-ésima estimativa da amplitude no n-ésimo intervalo será:

$$
\widehat{A}_{k}(n)=\sum_{i=0}^{N-1} \alpha_{i}\left|\tilde{y}_{k}(n-i)\right|,
$$

com $\alpha_{i}=$ conjunto de coeficientes, comprimento $N$, não negativos, não crescentes $\left(\alpha_{i} \geq \alpha_{i+1}\right)$ e $\sum_{i=0}^{N-1} \alpha_{i}=1$. Nestas condições, uma boa estimativa é obtida escolhendose $N$ grande e uma seqüência lentamente decrescente para $\alpha_{i}$. Por outro lado, caso as energias variem rapidamente, maior ênfase deve ser dada às componentes mais recentes da seqüência $\bar{y}_{k}$. Caso as energias mudem imprevisível e bruscamente, não é possível obter cancelamento do ruído, resultando no Descorrelacionador clássico. Enfim, caso haja períodos cujas energias mudem brusca e lentamente, o receptor poderá detectar este comportamento, alternando entre o modo descorrelação clássica e realimentado. Isto se aplica à região de alta relação sinal-ruído.

De modo similar, pode-se realizar a estimação e atualização das amplitudes em detecção PIC e SIC. Uma vez que estimativas de $\tau_{k}$ e $\phi_{k}$ em IC introduzem ruído no processo de cancelamento dos interferentes, degradando o desempenho global do sistema, o emprego de médias simples reduzirá a variância dos parâmetros a serem estimados [18]. Estas médias são tomadas sobre um número de bits de dados, $\mathfrak{n}$

$$
\widehat{A}_{k}=\frac{1}{\mathfrak{n}} \sum_{i=1}^{\mathfrak{n}} \widehat{A}_{k . i}
$$

onde: $\widehat{A}_{k, i}=$ parâmetro $A$, já estimado, para o usuário $k$ durante o $i$-ésimo intervalo de bit; $\widehat{A}_{k}=$ média da estimativa tomada sobre $\mathfrak{n}$ bits. Esta técnica pode ser empregada na redução da variância das estimativas dos parâmetros contanto que estas não sofram variações significativas durante o intervalo compreendido pelos $\mathfrak{n}$ bits utilizados no processo de mediação. Resultados numéricos de [4] e [18] para as estimativas de amplitude, atraso e fase mostraram que tomandose a média sobre um pequeno número de bits obtém-se redução significativa das respectivas variâncias, tanto em canal estático (AWGN) quanto em canais com desvanecimento multipercurso.

\section{CONCLUSÕES}

Este trabalho de revisão procurou mostrar o potencial incremento na capacidade dos sistemas de comunicação associado aos receptores multiusuários subtrativos (não lineares). Diferentemente da detecção convencional com filtro casado single-user, a detecção multiusuário utiliza as informações dos demais usuários ativos para anular os sinais que aparecem como interferência MAI quando da detecção do usuário de interesse. Em contrapartida, ter-se-á um aumento na complexidade dos sistemas. O receptor DS-CDMA convencional é extremamente sensivel ao efeito near-far, requerendo grandes cuidados com controle de potência e o projeto das sequiências de espalhamento a fim de obter aceitável desempenho, além 
de apresentar capacidade de sistema bem abaixo da capacidade de canal. Isto têm motivado pesquisas no campo de detecção multiusuário, objetivando reduzir ou mesmo eliminar a MAI.

Técnicas de Cancelamento de Interferência são empregadas quando informações confiáveis sobre os interferentes mais significativos no sistema estiverem disponíveis no receptor.

Questões importantes de pesquisa ainda remanescentes incluem considerações sobre estimadores não polarizados, confiabilidade na estimação de parâmetros, métodos de cancelamento parcial otimizados e canais com desvanecimento multipercurso objetivando atingir implementações estáveis e efetivas em receptores IC de baixa complexidade, alto desempenho e capacidade.

\section{AGRADECIMIENTOS}

Os autores desejam expressar seus agradecimentos aos revisores desse trabalho cujas sugestões permitiram aprimorar a sua apresentação geral.

\section{REFERÊNCIAS}

[1] T. Abrão and P. J. E. Jeszensky, "Detectores multiusuários para DS-CDMA - lineares fixos," Revista da Sociedade Brasileira de Telecomunicações, vol. 16. Dezembro 2001.

[2] J. Proakis, Digital Communications. McGraw-Hill, 2nd ed. 1989.

[3] M. K. Varanasi and B. Aazhang, "Multistage detection in asynchronous CDMA communications," IEEE Transactions on Communications, vol. 38, n.4, pp. 509-19. April 1990.

[4] P. Patel and J. M. Holtzman, "Analysis of a single sucessive interference cancellation scheme in a DS/CDMA system," IEEE Joumal on Selected Areas in Communications, vol. 12, n.5, pp. 796-07, June 1994.

[5] A. L. Johansson, Sucessive Interference Cancellation in DSCDMA Systems. PhD thesis. Department of Signals and Systems School of Electrical and Computer Engineering - Chalmers University of Technology, Göteborg, Sweden, 1998.

[6] M. Juntti, Multiuser Demodulation for DS-CDMA Systems in Fading Channels. PhD thesis, Dep. of Electrical Engineering University of Oulu, Finland, Sept. 1997.

[7] A. Duel-Hallen, "Decorrelating decision-feedback multiuser detector for synchronous CDMA channel," IEEE Transactions on Communications, vol. 41, n.2, pp. 285-90. Feb 1993.

[8] A. Duel-Hallen, "A family of multiuser decision-feedback detectors for asynchronous CDMA channels," IEEE Transactions on Communications, vol. 43, no. 2/3/4, pp. 421-34, Feb/Mar/April 1995.

[9] K. Kansanen, "Performance of mismatched parallel interference cancellation receivers in CDMA systems," Master's thesis, Dep. of Electrical Engineering University of Oulu, Finland, 1998.

[10] Z. e. A. Siveski, "Error performance of synchronous multiuser CDMA detector with multidimensional adaptive canceller," European Transactions Telecommunications Related Technologies, vol. 5, pp. 73-8, Nov./Dec. 1994.

[11] M. Pursley, "Performance evaluation for phase-coded spread spectrum multiple access communication - part i: System analysis," IEEE Transactions on Communications, vol. COM25, n.8, pp. 795-99, 1977.
[12] D. Chen and S. Roy, "An adaptive multiuser receiver for CDMA systems," IEEE Joumal on Selected Areas in Communications, vol. 12, no. 5, pp. 808-16, June 1994.

[13] R. Fantacci, "Proposal of an interference cancellation receiver with low complexity for DS/CDMA mobile communication systems," IEEE Transactions on Vehicular Technolgy, vol. 48, no.4. pp. 1039-46, July 1999.

[14] N. S. Correal, R. M. Buehrer, and B. D. Woerner, "A DSPbased DS-CDMA multiuser receiver employing partial parallel interference cancellation," IEEE Joumal on Selected Areas in Communications, vol. 47, no.4, pp. 613-30, April 1999.

[15] R. M. Buehrer and S. P. Nicoloso, "Comments on partial parallel interference cancellation for CDMA," IEEE Transactions on Communications, vol. 47, no.5, pp. 658-61, May 1999.

[16] G. Xue, J. Weng, T. Le-Ngoc, and S. Tahar, "Adaptive multistage parallel interference cancellation for CDMA," IEEE Joumal on Selected Areas in Communications, vol. 17, n.10, pp. 1815-27, October 1999

[17] P. G. Renucci, "Optimization of soft interference cancellation in DS-CDMA receivers," Master's thesis, Faculty of the Virginia Polytechnic Institute and State University, May 1998.

[18] R. M. Buehrer, The Application of Multiuser Detection to CelInlar CDMA. PhD thesis, Virginia Polytechnic Institute and State University, June 1996.

[19] N. S. Correal, Efficient Interference Cancellation Techniques for Advanced DS-CDMA Receivers. $\mathrm{PhD}$ thesis, Virginia Polytechnic Institute and State University - USA, July 1999.

[20] A. Kaul and B. D. Woerner, "Analytic limits on performance of adaptive multistage interference cancellation for CDMA," Electronics Letters, vol. 30, n.25, pp. 2093-95, 8 Dec. 1995.

[21] R. M. Buehrer and B. D. Woerner, "Analysis of an adaptive multistage interference cancellation for CDMA using improved gaussian approximation," IEEE Transactions on Communications, vol. 14, no. 10, pp. 1308-21, Oct. 1996.

[22] D. Divsalar, M. K. Simon, and D. Raphaeli, "Improved parallel interference cancellation for CDMA," IEEE Transactions on Communications, vol. 46, n.2, pp. 258-68, Feb. 1998

[23] R. M. Buehrer, K. Stavros, S. Striglis, and B. D. Woerner, "Analysis of DS/CDMA parallel interference cancellation with phase and timing errors," IEEE Joumal on Selected Areas in Communications, vol. 14, no. 8, pp. 1522-34, Oct. 1996.

[24] S. Moshavi, "Multi-user detection for DS-CDMA communications," IEEE Communications Magazine, pp. 124-36, Oct. 1996.

[25] S. Verdú, Multiuser Detection. Cambridge University Press, 1998.

[26] G. H. Golub and C. F. Van Loan, Matrix Computations. Johns Hopkins Univ Press (3rd edition), 1996.

[27] S. Haykin, Adaptive Filter Theory. Prentice Hall, 1996.

[28] S. Parkvall, Near-Far Resistant DS-CDMA Systems: Parameter Estimation and Data Detection. $\mathrm{PhD}$ thesis, Royal Institute of Technology, School of Electrical Engineering, Stockholm, Sweden, 1996.

[29] F. C. Cheng and J. M. Holtzman, "Effect of tracking error on DS/CDMA sucessive interference cancellation," in Proceedings of IEEE Communication Theory Mini-Conference, San Francisco, USA, pp. 166-70, 1994.

[30] P. Orten and T. Ottosson, "Robustness of DS-CDMA multiuser detectors," in Proc. IEEE Communication Theory MiniConference, Phoenix, USA, 1997.

Taufik Abrão é graduado, mestre e doutor em Engenharia Elétrica em 1992, 1996 e 2001, respectivamente, pela Escola Politécnica da Universidade de São Paulo. Atualmente é professor adjunto do Departamento de Engenharia Elétrica da Universidade Estadual de 
Londrina, PR. Comunicações sem fio, sistemas DS/CDMA quasesíncronos e detectores multiusuários para DS/CDMA constituem as principais áreas de pesquisa de seu interesse.

Paul Jean E. Jeszensky. Nascido em Nancy-França, obteve os títulos de Engenheiro Eletricista, Mestre em Engenharia Elétrica, Doutor em Engenharia Elétrica-Sistemas Eletrônicos e Livre Docente na área de Telecomunicaçōes, pela Escola Politécnica da USP em 1972, 1981, 1989 e 1992, respectivamente. Autor de cerca de 40 trabalhos técnicos/científicos, apresentados em Simpósios/Congressos/revistas especializadas, nacionais e internacionais. nas áreas de atuação acima. Professor da EPUSP desde 1978 e em dedicação exclusiva a partir de 1990, na área de Telecomunicações. Coordenador do LCS-Laboratório de Comunicações e Sinais do Departamento de Engenharia de Telecomunicações e Controle da EPUSP, no período de 1995/97 e 1999/2001. General Co-Chairmen do ITS'98-SBT/IEEE International Telecommunications Symposium, realizado em SP. Professor visitante da UPC-Universitat Politécnica de Catalunya (BarcelonaEspanha) em 1995 e da TUB-Technical University of Budapest (Budapest-Hungria) em 2001. Assessor especial da TELESPCelular para a implantação da digitalização na banda A de Telefonia Móvel Celular, em São Paulo, no período de 1997/98. Coordenador dos convênios de cooperação técnica entre a EPUSP e a Ericsson do Brasil, Motorola do Brasil e TELESP - Celular, desde 1999. Suas áreas de interesse para pesquisa incluem: comunicações sem fio em geral, sequiências de código para uso em sistemas DS/CDMA, sistemas DS/CDMA quase-síncronos e detecção multiusuário em DS/CDMA. 